\title{
Strength of 316L Stainless Steel Single-Lap Joints Brazed with Ni-Based Metallic Glass Foils for Corrosive Environments
}

\author{
DAVID J. KEMMENOE, ERIC A. THEISEN, and SHEFFORD P. BAKER
}

\begin{abstract}
In brazing, the choice of base metal, brazing filler metal (BFM), and braze process conditions involves complex tradeoffs among cost, mechanical strength, corrosion resistance, and others. In this work, the tradeoff between strength and corrosion resistance of $316 \mathrm{~L}$ stainless steel joints brazed with a newer "very corrosion-resistant" Ni-Cr-P-Mo-Si BFM and a more established "corrosion-resistant" Ni-Cr-Si-B BFM is quantitatively analyzed. Corrosion tests and microstructural analyses were performed using common practices. Joint strength was evaluated by testing brazed single-lap joints (SLJs) in tension following standardized procedures. However, conventional interpretations were found to be inadequate for quantitative comparisons. Therefore, the SLJ stress state was analyzed in detail and a complete interpretation was developed. Joint strength is shown to be determined by the SLJ geometry, base metal properties, and braze microstructure. This analysis was used to explain the occurrence of different failure modes (fast fracture, peeling, and base metal failure) and to make suggestions for improved methods for conducting and analyzing brazed SLJ tensile tests. The newer BFM is shown to provide significantly better corrosion resistance for a moderate reduction in mechanical strength.
\end{abstract}

https://doi.org/10.1007/s11661-021-06299-1

(c) The Minerals, Metals \& Materials Society and ASM International 2021

\section{INTRODUCTION}

BRAZING is an important metal joining technology that can cost-effectively join simple components into complex 3-D structures which would be impossible to form with fasteners, welding, or subtractive manufacturing. In brazing, a brazing filler metal (BFM) is melted above $450{ }^{\circ} \mathrm{C}$ to join two base metal components. The liquid BFM wets the surface of the solid base metal components, and joins them with a braze upon solidification. ${ }^{[1]}$

Brazing is an especially powerful technique when used to create complex layered structures such as plate-fin heat exchangers ${ }^{[2-5]}$ or lattice structures such as honeycomb panels. ${ }^{[4,6,7]}$ An example of brazed joints in a commercial plate-fin heat exchanger is shown in Figure 1. In this application, layers of flat and stamped

DAVID J. KEMMENOE is with the Sibley School of Mechanical and Aerospace Engineering, Cornell University, Upson Hall, Ithaca, NY, 14853. ERIC A. THEISEN is with the Metglas Inc., 440 Allied Drive, Conway, SC, 29526. SHEFFORD P. BAKER is with the Sibley School of Mechanical and Aerospace Engineering, Cornell University and also with Department of Materials Science and Engineering, Cornell University, Bard Hall, Ithaca, NY, 14853. Contact e-mail: shefford.baker@cornell.edu.

Manuscript submitted October 29, 2020; accepted April 7, 2021.

Article published online June 2, 2021 sheet metal are stacked with BFM foils in between. A single thermal cycle transforms these inexpensive sheet metal layers into a high-thermal-efficiency structure consisting of a large number of cross-current flow channels. The only other technique capable of creating such topologically complex metallic structures is additive manufacturing, which is slow and cost-prohibitive for large structures or large production volumes.

In these and many other applications, both high strength and high corrosion resistance are required, often at high temperatures. ${ }^{[2,4]}$ Accordingly, such components are commonly manufactured using stainless steel (SS) base metals brazed with Ni-Cr-based BFMs. This choice of materials leads to two important design decisions. The first is the choice of BFM composition, which involves intrinsic tradeoffs among many engineering variables (mechanical properties, corrosion resistance, brazing process variables, cost, etc.). For example, Ni-Cr-based BFMs typically include B, Si, and/or $\mathrm{P}$ to lower BFM melting temperature and to increase liquid metal fluidity. ${ }^{[1]}$ These melting point depressants (MPDs) commonly react with metallic elements during brazing to form intermetallic compounds (IMCs), which can lead to lower strength because they are brittle, concentrate stresses, and provide low-toughness fracture paths through the material. $^{[3-6,8-10]}$ IMCs can also lower corrosion resistance by concentrating $\mathrm{Cr}$, removing it from phases where it is 
needed for effective corrosion resistance.$^{[3,7,9,11]}$ Corrosion resistance can be increased by increasing $\mathrm{Cr}$ content but generally at the expense of higher brazing temperatures.

The second important design decision is the form of the BFM. For layered structures, Ni-Cr-based BFMs can be applied in paste form (metal particles in an organic binder) or as amorphous foil. Amorphous brazing foils are created by rapid solidification and have a number of advantages for layered structures. ${ }^{[3,4,9]}$ Such foils can be stamped and cut into precise shapes which can be placed in their final locations robotically. With preplaced foils, the thermal cycle must only melt and resolidify the BFM to form brazed joints, rather than relying on capillary flow to pull the BFM into position, allowing larger and more homogenous braze joints. Use of foil also requires less BFM, which reduces base metal erosion and the volume of IMCs, enables control of braze thickness by selection of an appropriate foil thickness, and eliminates impurities and voids introduced by the organic binders necessary with paste. Finally, such foils are homogeneous on the microscopic level and have a narrower melting range, reducing the risk of inhomogeneous melting and flow, known as liquation. These features reduce defects and increase the fraction of the joint area that is actually brazed, reducing the variability in joint strength and decreasing part rejection rates. ${ }^{[4,9]}$

Significant effort has been undertaken to develop Ni-Cr-based BFM alloys optimized for different engineering requirements in a range of layered SS brazements. In the work presented here, our objective was to provide a detailed analysis of the tradeoffs associated with the choice of two different amorphous foil BFMs developed for their corrosion resistance in SS joints, namely the established "corrosion-resistant" MBF-51 and the recently-developed "very corrosion-resistant" MBF-67, available from Metglas, Inc. (MBF = Metglas Brazing Foil). The compositions of these alloys, along with a "standard" reference alloy, MBF-20, and equivalent compositions standardized by the American Welding Society (AWS) under its "BNi" designation system ${ }^{[1]}$ are shown in Table I.

The well-established MBF-20/BNi-2 composition was designed for strength and manufacturability. ${ }^{[1]}$ It uses $\mathrm{Si}$ and $\mathrm{B}$ as MPDs, and since $\mathrm{Si}$ is soluble in Ni up to $6 \mathrm{wt}$ $\mathrm{pct}^{[12]}$ and $\mathrm{B}$ diffuses rapidly out of the braze, it is possible to form a strong IMC-free joint consisting of a ductile single-phase braze. ${ }^{[3,8]}$ However, as B diffuses out of the braze along SS grain boundaries, it forms chromium borides $\left(\mathrm{Cr}_{x} \mathrm{~B}_{y}\right)$ in the base metal, consuming $\mathrm{Cr}$ from the $\mathrm{SS}$ and leaving a $\mathrm{Cr}$-depleted region that is more open to corrosive attack. ${ }^{[3,7,9]}$ These IMCs can also degrade strength. ${ }^{[3,8]}$ The conditions under which IMC-free brazes can be produced, as well as the distributions of $\mathrm{Cr}_{x} \mathrm{~B}_{y}$ and their effects on properties, have been studied in detail (e.g., Reference 10 and references cited therein).

In the 1990s, the MBF-51/BNi-5b alloy was developed specifically for higher corrosion resistance by increasing $\mathrm{Cr}$ content and lowering the $\mathrm{B}$ concentration to the minimum needed to manufacture an amorphous

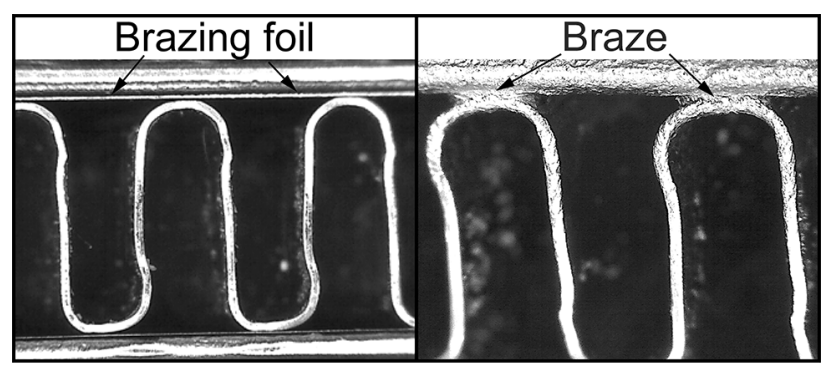

(a)

(b)

Fig. 1-Portion of a commercial plate-fin heat-exchanger design made from $316 \mathrm{~L}$ stainless steel showing (a) MBF-51 amorphous brazing foils between the stainless steel layers before and $(b)$ finished brazes after brazing (unpublished work of the authors).

foil. ${ }^{[3,7]}$ Again, B is able to diffuse out of the braze, leaving a ductile single-phase braze with joint strength comparable to that of joints made using MBF-20/BNi-2 (e.g., IMC-free joints made with VZ2120 and VZ2150 amorphous foil BFMs from Vacuumschmelze, which are similar to $\mathrm{MBF}-20$ and $\mathrm{MBF}-51$, respectively, have similar strength $\left.{ }^{[11]}\right)$. Compared to MBF-20, MBF-51 achieves higher corrosion resistance and similar strength at the expense of higher brazing temperatures.

More recently, there has been a significant impetus to create $\mathrm{Ni}-\mathrm{Cr}$-based BFMs with even higher corrosion resistance $^{[2]}$ as well as lower melting temperature compared to MBF-51, and several such alloys have been developed. ${ }^{[7,9,11]}$ Higher corrosion resistance is achieved by further reductions in $\mathrm{B}$ and increases in $\mathrm{Cr}$, and lower melting point is achieved by replacing $\mathrm{B}$ and $\mathrm{Si}$ with $\mathrm{P}$ as the primary MPD. MBF-67 (no direct AWS equivalent) is an example of this class of BFM. This alloy class has been shown to have increased corrosion resistance over previous BFMs. ${ }^{[11]}$ However, $\mathrm{P}$ is known to react with metallic elements to form IMCs that reduce joint strength. ${ }^{[6,8,9]}$ Thus, compared to MBF-51, MBF-67 is designed to achieve very high corrosion resistance and lower melting temperatures at the expense of mechanical strength.

In this work, we quantify the improvement in corrosion resistance and reduction in joint strength when going from MBF-51 to MBF-67. In addition, we attempt to determine if braze joint mechanical performance can be improved in joints made using MBF-67 by increasing braze temperature and time to allow MPDs to diffuse out of the braze, thereby reducing the size and density of IMCs leading to more ductile and stronger joints.

Despite the potential importance of these BFMs, particularly in SS automotive exhaust heat exchanger applications, ${ }^{[1]}$ very little work has been done to understand their behavior. Rabinkin et al. ${ }^{[3]}$ prepared 316L SS single-lap joints using MBF-51 and showed that joint strength was low and samples failed in the braze when the brazing temperature/time was not high/long enough for $\mathrm{B}$ and $\mathrm{Si}$ to diffuse out of the braze such that IMCs $\left(\mathrm{Cr}_{x} \mathrm{~B}_{y}, \mathrm{Ni}_{x} \mathrm{Si}_{y}, \mathrm{Mo}_{x} \mathrm{Si}_{y}\right)$ formed in the braze. In contrast, when the brazing temperature/time was high/long enough for B and Si to diffuse 
Table I. Composition and Melting Characteristics of the Amorphous Brazing Foils and 316L Stainless Steel Base Metal Used in This Study Along With the Equivalent AWS Classifications

\begin{tabular}{|c|c|c|c|c|c|c|c|c|c|c|c|c|}
\hline & \multirow[b]{2}{*}{$\mathrm{MBF}$} & \multirow{2}{*}{ AWS } & \multicolumn{8}{|c|}{ Nominal Composition (Wt Pct) } & \multicolumn{2}{|c|}{ Melting Temperature ${ }^{\circ} \mathrm{C}\left({ }^{\circ} \mathrm{F}\right)$} \\
\hline & & & $\mathrm{Cr}$ & $\mathrm{Fe}$ & B & $\mathrm{Si}$ & $\mathrm{P}$ & Mo & & & Solidus & Liquidus \\
\hline \multirow[t]{4}{*}{ Braze Alloy } & 20 & $\mathrm{BNi}-2$ & 7.0 & 3.0 & 3.2 & 4.5 & - & - & & & $969(1776)$ & $1024(1875)$ \\
\hline & 51 & $\mathrm{BNi}-5 \mathrm{~b}$ & 15.0 & - & 1.4 & 7.3 & - & - & & & $1030(1886)$ & $1126(2058)$ \\
\hline & 67 & —* & 25.0 & $<1$ & $<0.5$ & 1.5 & 6.0 & 1.5 & & & $890(1634)$ & $970(1778)$ \\
\hline & ASTM & SS & \multicolumn{2}{|c|}{$\mathrm{Cr}$} & $\mathrm{Ni}$ & & \multicolumn{2}{|c|}{ Mo } & $\mathrm{Mn}$ & $\mathrm{Fe}$ & Solidus & Liquidus \\
\hline Base Metal & $666-15$ & $316 \mathrm{~L}$ & \multicolumn{2}{|c|}{16.0 to 18.0} & 10.0 to & & \multicolumn{2}{|c|}{2.0 to 3.0} & 2.0 & $\sim 66$ & $1371(2500)$ & $1399(2550)$ \\
\hline
\end{tabular}

*MBF-67 does not have an AWS standard. However, MBF-67 is similar to BNi 12.

out of the braze (note that it is well known that B diffuses much more readily than $\mathrm{Si}$ ), failure occurred in the base metal at much higher loads. They also reported (without evidence) that corrosion resistance in four different corrosive media was similar to that of the $316 \mathrm{~L}$ base metal alone. This may well have been true given that they brazed their corrosion test samples for 2.5 hours at $1190{ }^{\circ} \mathrm{C}$ followed by annealing at $1100{ }^{\circ} \mathrm{C}$ for an additional 3 hours and may thus have created fully homogeneous joints. However, such long braze cycles are not technologically relevant, emphasizing the need for new BFM alloys.

In contrast, Hartmann and Marsilius ${ }^{[11]}$ prepared 316L SS butt joint samples using VZ2150 and VZ2177 amorphous foil BFMs (produced by Vacuumschmelze $\mathrm{GmbH}$ ) that have compositions similar to MBF-51 and MBF-67, respectively. They found that joints made with VZ2150 failed near the base metal ultimate tensile strength while joints made with VZ2177 failed in the braze at much lower stresses. While they did not present a microstructural analysis, they attributed the lower strength of joints made with VZ2177 to the expected brittle phosphide IMCs. They conducted corrosion tests meant to simulate gasoline engine exhaust conditions and showed that brazes made with both VZ2150 and VZ2177 had better corrosion resistance than brazes made with foils having compositions similar to $\mathrm{BNi}-2$. However, despite showing that brazes made with VZ2177 had better corrosion resistance than those made with VZ2150, they concluded only that both braze types have "very good corrosion resistance" in their test conditions. Thus, while the studies of Rabinkin et al. and Hartmann and Marsilius broadly confirm expected trends, they do not provide quantitative comparisons of the tradeoffs among BFM composition, braze cycle, strength, and corrosion resistance for these classes of BFM alloy.

To understand the engineering tradeoffs associated with a particular choice of BFM, base metal, and brazing process, it is necessary to understand the relationships among processing variables, microstructure, and properties using accurate and reproducible test methods. Unfortunately, very few brazing studies include all three of these components. Furthermore, while quantitative corrosion tests are available and microstructural analyses of metallic structures are very well established, mechanical testing of brazed joints has not yet reached the state where testing and interpretation are sufficiently well standardized that results from different laboratories can be directly compared.

This is not for want of trying. In 1963, a group commissioned by the AWS noted that the variety of tests that had hitherto been used could return an order of magnitude spread in "strength" for a given base metal/BFM combination and recommended that a "single-lap shear test" be established as the standard for evaluating braze joint strength. ${ }^{[13]}$ This standard was updated to AWS C3.2 in 1982 and has been periodically updated, most recently in 2019. ${ }^{[14]}$ AWS C3.2-19 specifies a single-lap joint (SLJ) sample geometry as shown in Figure 2 for testing in tension. It specifies sample geometry (Figure 2), surface finish, tensile test procedures, and how the data should be reported. Although AWS C3.2 now includes standards for testing of butt joints and double-lap joints, the SLJ geometry remains the most common configuration used for mechanical testing of braze joints because it is simple, economical, reproducible, and thought to be more representative of real brazed joints than other test geometries. ${ }^{[13,15-19]}$

Nevertheless, few reports of brazed SLJ tests include data that follow the AWS C3.2 standard, and those that do often provide interpretations that are not consistent with what is known about stress states and failure modes in such tests. After considerable review of the published literature regarding tensile testing of SLJs, both those formed by brazing and those formed using adhesives, we attribute this primarily to oversimplified and/or inaccurate descriptions of the stress state.

SLJ samples are created by taking two "half-dogbone" plates with rectangular cross-sections of thickness $t$ and width $w$, overlapping them over a length $o$ and brazing them together (Figure 2). AWS C3.2 specifies that samples with a fixed set of overlap ratios $(o / t)$ be tested and the results reported both as the average engineering tensile stress in the base metal at failure (the load at failure divided by the original cross-sectional area, $w t$, of the unloaded gauge sections), a quantity that we will refer to as the "SLJ strength" or $\sigma_{\mathrm{SLJ}}$, and as the average engineering shear stress in the braze at failure (the load at failure divided by the original area, ow, of the unloaded braze), which we refer to as $\tau_{\mathrm{SLJ}}$. Although the purpose of AWS C3.2 is to describe methods and not 


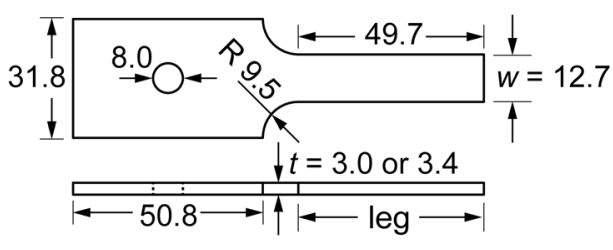

(a) Half-dogbone blank

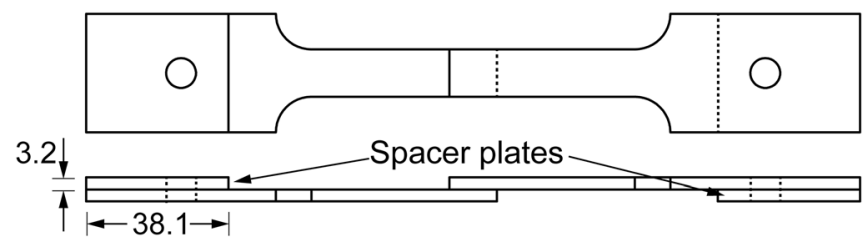

(c) Brazed single-lap joint with spacer plates

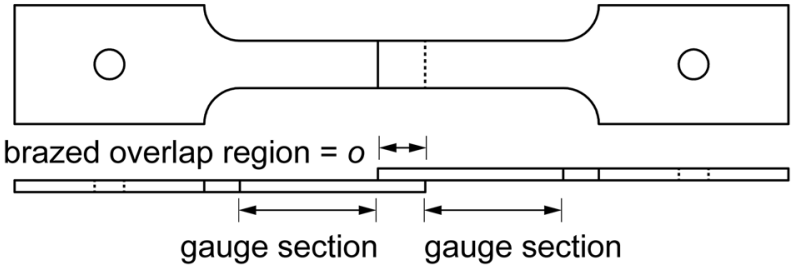

(b) Brazed single-lap joint

Fig. 2 - Geometry and dimensions (mm) of single-lap joint (SLJ) samples following AWS C3.2 ${ }^{[14]}$ : (a) half-dogbone blank, (b) brazed SLJ, and (c) SLJ with spacer plates for testing. The reduced width portion of a half-dogbone is referred to as the "leg" (a), the portion of the SLJ with overlapping plates is referred to as the "overlap" section (b), and the remainder of the leg that is not part of the overlap section is referred to as the "gauge" section (b).

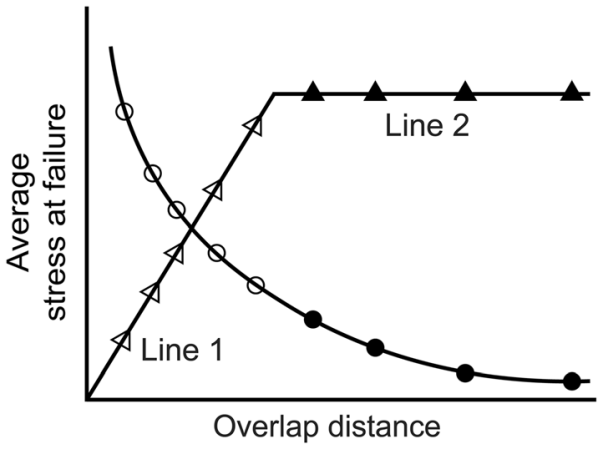

Fig. 3-Schematic showing expected behavior of brazed SLJs according to AWS C3.2 (adapted from Ref. [14]). Triangles represent average engineering tensile stress in the base metal at failure and circles represent average shear stress in the braze at failure. Open symbols represent braze failure while filled symbols represent base metal failure.

interpretation of the test results, the standard states that the results will appear as shown in Figure 3, where $\sigma_{\mathrm{SLJ}}$ can be described by a "two-straight-line function," increasing linearly with increasing overlap length at low $o / t$ and becoming constant with overlap length above some point, while the average shear stress at failure $\tau_{\mathrm{SLJ}}$ declines monotonically with increasing $o / t$. Furthermore, the "two straight lines" are said to correspond to failure in the braze and failure in the base metal for low and high $o / t$, respectively.

Perhaps due to expectations described in the AWS standard, certain conventional interpretations have arisen that cloud both understanding and application of brazed SLJ tensile tests. First, the standard refers to the SLJ test as a shear test ("Test specimen and procedures of the testing of single-lap joints in shear"). While "shear" may have been intended to indicate that the load is initially applied parallel to the braze surface, the requirement for reporting $\tau_{\mathrm{SLJ}}$ implies that failure is somehow related to a uniform shear stress in the braze. Indeed, many authors report only $\tau_{\mathrm{SLJ}}$ (e.g., References $3,5,18$, and 20), and often only at a single $o / t$ (e.g., References 3 and 5), as if it represented a critical stress for failure of the braze material. Similar reporting practices are found for tests involving brazed double-lap joints $^{[21]}$ and geometrically-modified SLJs. ${ }^{[15,22]}$ However, it has been more than 75 years since Goland and Reissner published their 2-D elastic stress analysis, ${ }^{[23]}$ which indicates that the stress state along the braze in an SLJ under tension is not at all similar to uniform shear. Instead the stresses are concentrated near the ends of the joint with normal stresses perpendicular to the braze being larger than the shear stresses. Surprisingly, only a few authors have considered the effects of realistic stress states on the mechanical behavior of brazed SLJs. ${ }^{[16,17,19}$ ${ }^{24-26]}$ Finally, we note that if $\tau_{\mathrm{SLJ}}$ declines monotonically with $o / t$ as shown in Figure 3, it obviously cannot represent a critical value.

Second, due to the eccentric loading, the joint rotates as load is increased, leading to significant changes in the stress state. ${ }^{[23,24,27,28]}$ The degree of rotation at a given load depends on both $o / t$ and the properties - particularly the amount of plastic deformation - of the base metal. Thus, deformation and failure of brazed SLJs is a geometrically nonlinear problem that is much more complicated than even a complex 2-D elastic analysis like that of Goland and Reissner ${ }^{[23]}$ would predict. For example, two samples with identical geometry $(o / t)$ joined with the same BFM but at different braze temperatures could show different strengths arising from different amounts of rotation due to the effects of the braze process on base metal properties - an effect not due to the characteristics of the BFMs.

Third, while the "two-line" behavior of $\sigma_{\text {SLJ }}$ in brazed joints has been reported, ${ }^{[13,16,25,29]}$ in many cases it is not observed. ${ }^{[13,16-19,29]}$ In some cases, the "two-line" interpretation is imposed, even though the data clearly do 
not support it. ${ }^{[16,29]}$ Furthermore, in the few papers that actually do report both $\sigma_{\mathrm{SLJ}}$ and the location of failure for a sufficiently wide range of $o / t$, it is evident that neither braze failures nor base metal failures are restricted to the segments of the curve specified in Figure 3. ${ }^{[13,16,25,29]}$

While a handful of authors have acknowledged that the actual stress state in a brazed SLJ is more complicated than the simple shear considered in AWS C3.2, ${ }^{[16,17,19,24-26]}$ some did not utilize this knowledge in their analysis, ${ }^{[16,17]}$ only a few used at least some aspects of the realistic stress state to interpret their SLJ data, ${ }^{[19,25,26]}$ and even fewer included geometric nonlinearity in their analysis. ${ }^{[19,26]}$ Interestingly, much work has been done to understand the actual stress state and its effects on SLJs bonded with polymer adhesives (e.g., References 30 and 31), and we will show that much of that work can be applied directly to brazed SLJs.

In the present paper, we present the results of a detailed study of the mechanical properties and corrosion resistance of joints made from $316 \mathrm{~L} \mathrm{SS}$ brazed with "corrosion-resistant" MBF-51 and with the newer "very corrosion-resistant" MBF-67. These base metal/BFM combinations are of interest in highly corrosive applications such as high-sulfur-containing diesel exhaust gas recovery units and ammonia refrigeration heat exchanger units. In contrast to previous studies, we

- include changes in process variables, a detailed microstructural analysis, and accurate measurements of strength and corrosion so that direct quantitative comparisons can be made;

- conduct tension tests to characterize mechanical properties of both the base metal and of SLJs, utilizing the intent of the AWS C3.2 standard, but expanding it such that these results can be duplicated and/or compared across laboratories; and

- develop a complete understanding of the stress state, including the effects of geometric nonlinearity, and use it in interpreting results.

MBF-51 joints were processed using a braze cycle suggested by the manufacturer to produce a single-phase braze resulting in high joint strength, while MBF-67 joints were processed using a lower-time-and-temperature braze cycle commonly used for production. We also subjected MBF-67 joints to the same braze cycle as MBF-51 to investigate whether the higher temperature and longer time could create a more mechanically robust braze joint.

Joint strength and failure characteristics were determined by testing SLJs to failure in uniaxial tension. We used the sample geometry specified in AWS C3.2, but with a wider range of overlap ratios to capture the full range of behavior. In addition, to aid in data interpretation, load-displacement data were recorded throughout each test, in situ video images were recorded for a selected subset, and still photographs were taken post facto. Corrosion was characterized by mass loss in a 25 pct phosphoric acid solution for samples brazed using MBF-51 and MBF-67, and for comparison, MBF-20. While this was a rather severe test, ${ }^{[3]}$ it served to demonstrate distinct differences among the BFMs. We used secondary electron scanning electron microscopy (SEM) to ascertain the overall phase and grain morphology and to investigate crack paths and fracture surfaces, energy-dispersive X-ray spectroscopy (EDX) to determine phase composition, and nanoindentation to determine the hardnesses of the different phases present.

To interpret the data, we considered the actual stress state and its variation with both load and overlap length. Since a concise description of the stress state does not exist, we provide one assembled from a variety of sources. We compared the load-displacement data, the deformation behavior and crack motion captured in video, the phase composition, hardness, and morphology, the crack paths and fracture surfaces, and the expected stress state evolution with load and overlap length to obtain a complete picture of structure-property relationships in the three different brazement systems.

We find that the conventional interpretation of brazed SLJ tests is indeed incorrect. The SLJ strength, $\sigma_{\mathrm{SLJ}}$, varies strongly with overlap length (it is the most consequential variable in our study) but this is accounted for by sample rotation, not primarily by the change in braze area. We find a "two-straight-line function" behavior as shown in Figure 3, but show that the transition from one line to the other is not necessarily associated with a change in failure mechanism. We also find that braze failures can occur by fast fracture (unstable crack propagation) or by peeling (stable crack propagation) and that joints can fail by peeling regardless of the overlap length - that is, there is no transformation to base metal failure with increasing overlap length for such samples. Finally, we find no valuable application for $\tau_{\mathrm{SLJ}}$.

At longer overlaps, the joint strength, $\sigma_{\mathrm{SLJ}}$, in samples brazed with MBF-51 was determined by the ultimate tensile strength of the base metal, $\sigma_{\mathrm{UTS}}$, while samples brazed with MBF-67 failed by peeling in the braze at $\sigma_{\mathrm{SLJ}}<\sigma_{\mathrm{UTS}}$ with no effect of the braze cycle. At low $o / t$, $\sigma_{\mathrm{SLJ}}$ varied strongly with $o / t$ for all samples. At a given $o / t$ in this regime, samples brazed with MBF-51 were strongest, but samples brazed with MBF-67 at higher temperature and longer time were significantly stronger than those brazed using the standard braze cycle for this BFM. We find that joints made with MBF-67 have higher corrosion resistance than those made with MBF-51, such that, for the longest overlap a switch from MBF-51 to MBF-67 significantly reduces the corrosion rate $(\approx 57 \mathrm{pct})$ in exchange for a modest $(\approx$ 22 pct) decrease in joint strength.

Overall, we show that variation in joint strength and failure behavior can be explained by three features:

- Joint geometry-particularly $o / t$, which plays a primary role in determining the stress distribution. In our studies, $\sigma_{\mathrm{SLJ}}$ depends more strongly on overlap ratio than on choice of BFM or braze cycle.

- Base metal properties-particularly yield strength and strain hardening, which determine how the geometry and stress state evolve with load. 
- Braze and braze fillet microstructure-particularly the IMC structure and its effect on fracture initiation/propagation and corrosion.

By understanding how the combination of joint geometry, materials, and braze cycle conspire to affect these features, it is possible to understand how they affect both strength and failure modes. We find the SLJ tensile test to be quite informative using this analysis and suggest that this approach to interpreting SLJ results can facilitate the development of higher quality and lower cost brazed devices such as SS plate-fin heat exchangers.

\section{EXPERIMENTS AND RESULTS}

Brazed SLJs were formed by joining 316L SS with MBF-51 or MBF-67 (Table I) and then tested to failure in uniaxial tension. Microstructures of braze joints made using these two BFMs were characterized in detail. Corrosion resistance was measured of joints made with these BFMs, along with MBF-20 for comparison.

\section{A. Sample Fabrication and Mechanical Testing}

Single-lap joints were produced for mechanical testing using the geometry specified in the AWS C3.2 standard ${ }^{[14]}$ First, half-dogbone blanks (Figure 2(a)) were laser cut from electropolished 316L SS plate with nominal thickness $t=3.2 \mathrm{~mm}(1 / 8 \mathrm{in}$.- actual either 3.0 or $3.4 \mathrm{~mm}$ ) to a gauge section width of $w=12.7 \mathrm{~mm}$ $(1 / 2$ in.). The cut edges of the blanks were then smoothed using an 80 grit abrasive paper and repassivated using CitriSurf 2050. The electropolished surfaces had roughnesses of 0.25 to $0.35 \mu \mathrm{m}$ as determined using a surface profilometer. To make each SLJ sample, two blanks of the same thickness were cleaned in acetone, then overlapped into an SLJ configuration (Figure 2(b)) with a $38 \mathrm{~mm}(0.0015$ in.) thick brazing foil between them and held in place for brazing with a $2.5 \mathrm{~kg}$ weight placed on the overlapped blanks.

Each assembly was vacuum furnace brazed at $10^{-5}$ Torr using one of the two thermal cycles shown in Figure 4. Maximum temperatures were $1195{ }^{\circ} \mathrm{C}$ for 60 minutes or $1090{ }^{\circ} \mathrm{C}$ for 15 minutes, which we refer to as

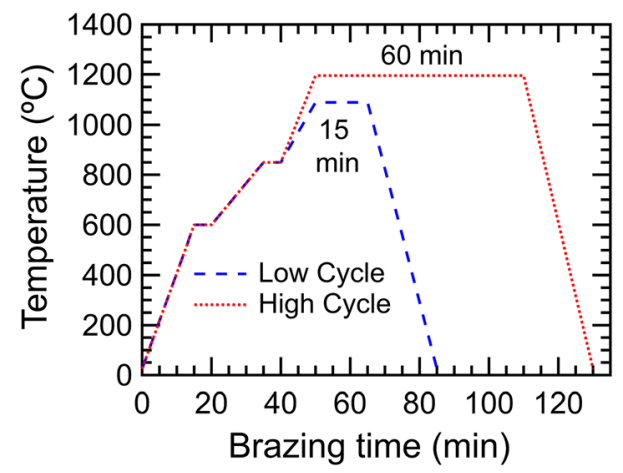

Fig. 4-Thermal cycles used for brazing. "Low Cycle" $=1090{ }^{\circ} \mathrm{C}$ for 15 min. "High Cycle" = $1195{ }^{\circ} \mathrm{C}$ for $60 \mathrm{~min}$.
"High Cycle" and "Low Cycle," respectively. Both heating schedules include holds at $600{ }^{\circ} \mathrm{C}$ and $850{ }^{\circ} \mathrm{C}$ to ensure thermal equilibration before ramping to the final brazing temperature. Braze thickness was determined by BFM foil thickness and the applied pressure from the $2.5 \mathrm{~kg}$ weight placed on the overlapped blanks. At the completion of the brazing cycle, the furnace cooled passively, reaching room temperature in approximately 20 minutes.

Three sets of brazed SLJs were fabricated, one using MBF-51 under High-Cycle conditions, one using MBF-67 under Low-Cycle conditions, and one using MBF-67 under High-Cycle conditions. We refer to these sample sets as $51 \mathrm{H}, 67 \mathrm{~L}$, and $67 \mathrm{H}$, respectively. The Low-Cycle braze temperature was too low to effectively braze using MBF-51. Each set consisted of SLJs with overlap lengths, $o$, set to provide a range of nominal overlap ratio $(o / t)$ values. Two samples were made at each overlap ratio for nominal $o / t$ values of $0.5,1,2$, and 4 (overlap lengths 1.6 to $12.7 \mathrm{~mm}$ or $1 / 16$ to $1 / 2 \mathrm{in}$.) and one sample apiece for $o / t$ values of 6,8 , and 12 (overlap lengths of 19 to $38 \mathrm{~mm}$ or $3 / 4$ to $3 / 2 \mathrm{in}$.). (AWS C3.2 suggests an $o / t$ range of 0.38 to 4.0 , but we found that larger values were needed to capture the full range of behavior.) Actual $o$ and $t$ values were measured using calipers for each finished sample and actual $o / t$ values are reported below.

For mechanical testing, 3.2-mm (1/8 in.)-thick spacer plates (Figure 2(c)) with $5.8 \mathrm{~mm}(1 / 4$ in.) long pins were used to load each SLJ into standard wedge grips. A screw-driven load frame, with a $50 \mathrm{kN}$ load cell, was used to pull each SLJ in tension at a constant crosshead displacement rate of $1 \mathrm{~mm} / \mathrm{min}$ until failure while recording load and displacement. Videos of several of the deforming joints were recorded for subsequent analysis.

Per AWS C3.2, $\sigma_{\mathrm{SLJ}}$ (average engineering tensile stress in the base metal at failure) and $\tau_{\mathrm{SLJ}}$ (average engineering shear stress in the brazing filler metal at failure) are presented as a function of overlap ratio in Figure 5. For each set of samples, $\sigma_{\text {SLJ }}$ (Figure 5(a)) increases linearly with $o / t$ up to some value, after which it is nearly constant, while $\tau_{\text {SLJ }}$ (Figure 5(b)) decreases monotonically with increasing $o / t$. The $51 \mathrm{H}$ samples are significantly stronger than both $67 \mathrm{H}$ and $67 \mathrm{~L}$ samples at all overlap ratios. Interestingly, the $67 \mathrm{H}$ samples were stronger than the $67 \mathrm{~L}$ samples, but only for $o / t$ values $<$ 5 . For $o / t$ values $>5$ the SLJ strength was similar in $67 \mathrm{~L}$ and $67 \mathrm{H}$ samples.

The yield stress, $\sigma_{\text {yield }}$, of the SS base metal is expected to be affected by the braze cycle; thus, $\sigma_{\text {yield }}$ was determined as follows: six tensile test 'dogbone' samples were laser cut from $316 \mathrm{~L}$ SS plate. In plan view, these samples have the shape shown in Figure 2(b), but each one is made from a single plate having constant thickness. Each has $t=3.1 \mathrm{~mm}$, gauge length 51.8 $\mathrm{mm}$, and gauge width $12.7 \mathrm{~mm}$. One pair of these tensile test samples was subjected to Low-Cycle and another pair to High-Cycle thermal cycling, while the final pair was maintained in the as-received condition. All six samples were tested to failure in tension using the same procedures as were used for the SLJs. 


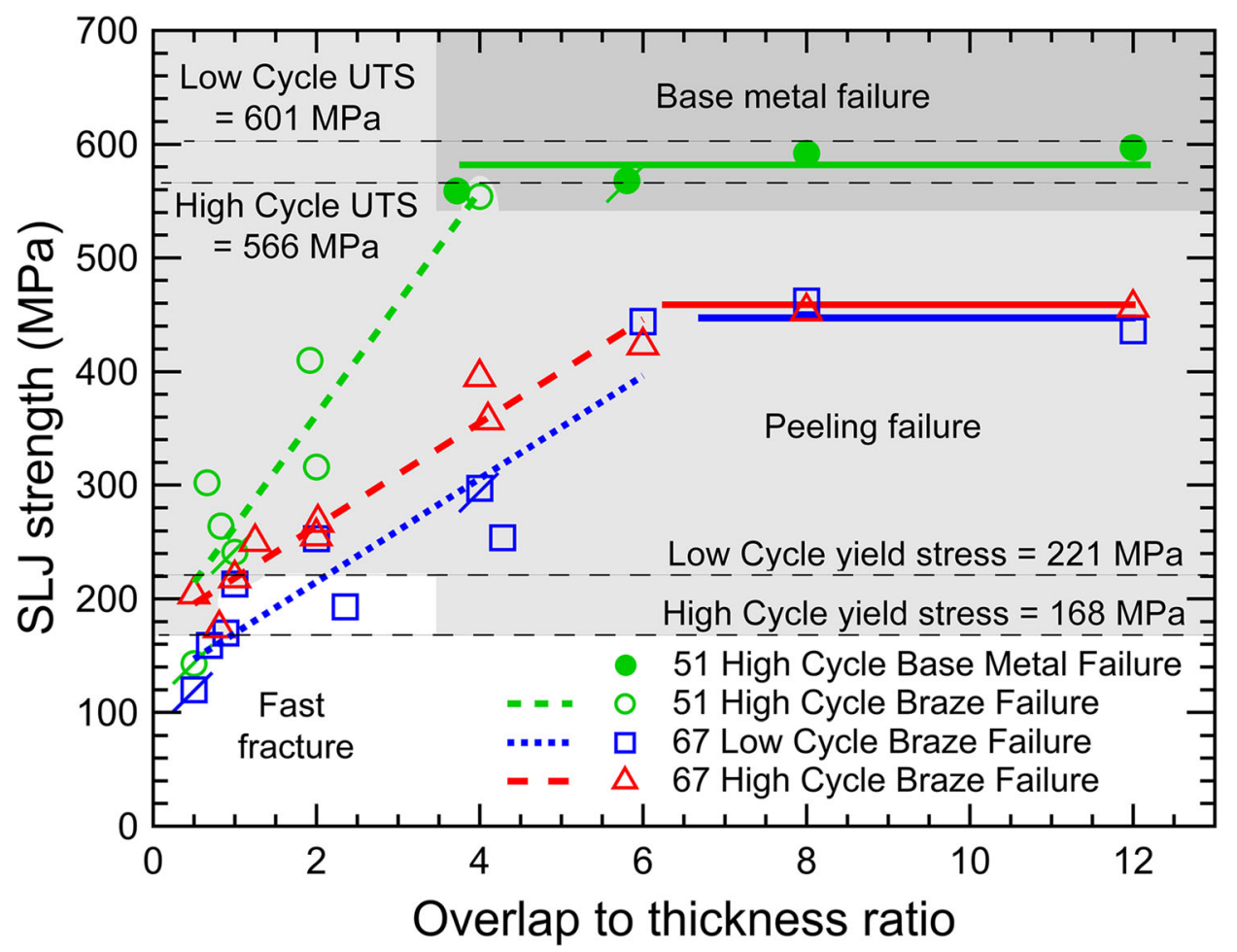

(a)

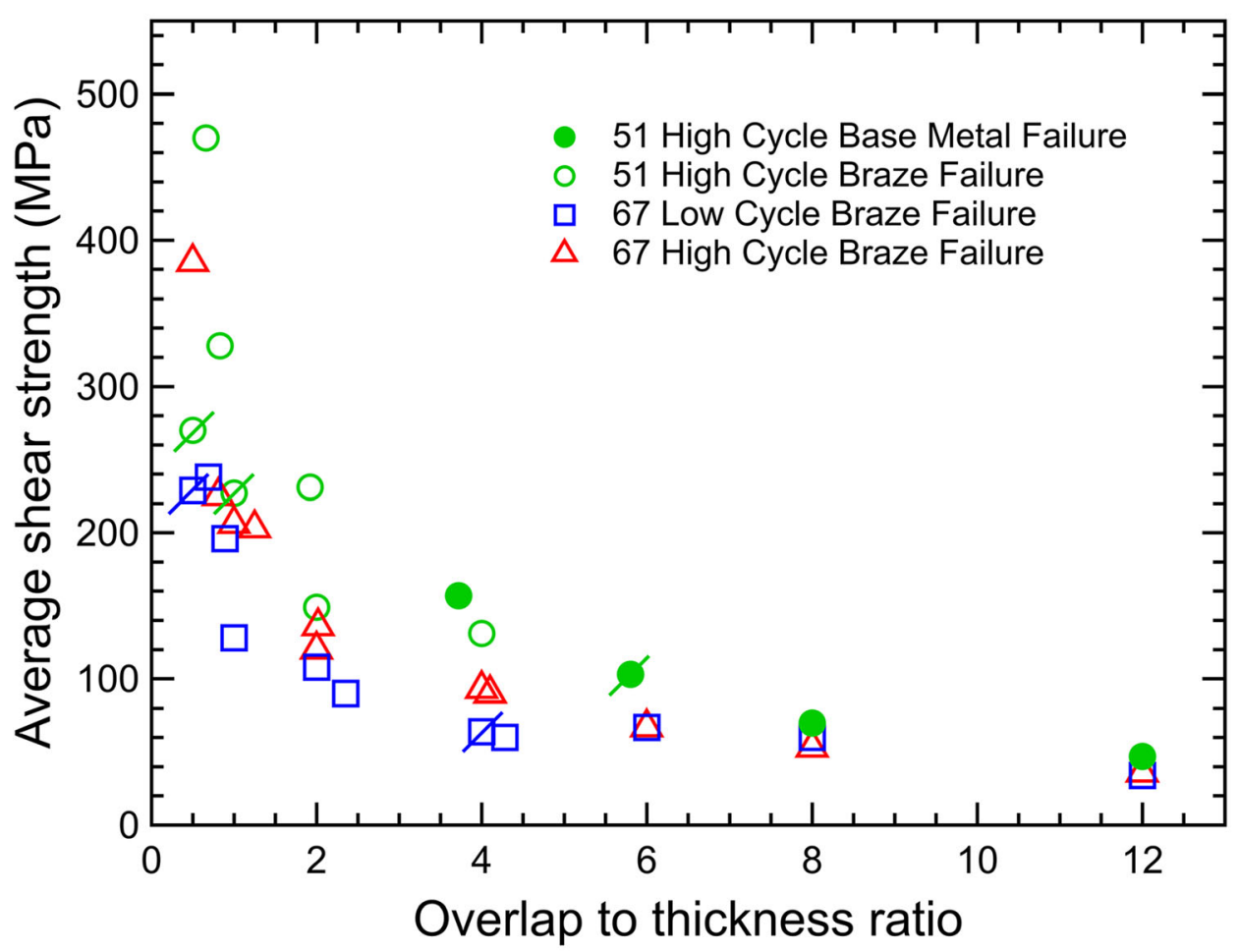

(b)

Fig. 5- (a) SLJ strength (maximum engineering tensile stress in the gauge section) and (b) average shear strength (maximum applied force divided by nominal overlap area) $v s$. overlap ratio $(o / t)$ for the three sets of brazed 316L SS SLJs. Open markers represent braze failure and closed symbols denote base metal failure. Shading in (a) indicates failure mode. Symbols with a slash through them represent samples where the overlap was not fully wet out during brazing. Fits of straight lines to the low $o / t$ data in (a) give $R^{2}$ values of $0.84(51 \mathrm{H}), 0.84(67 \mathrm{~L})$, and 0.94 $(67 \mathrm{H})$. 


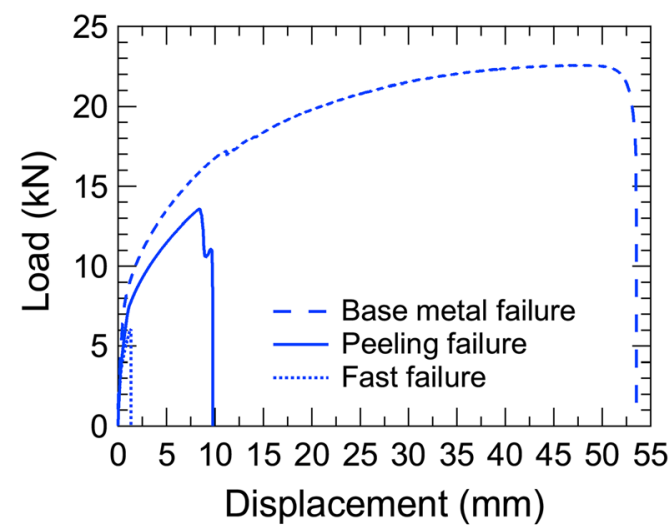

(a)

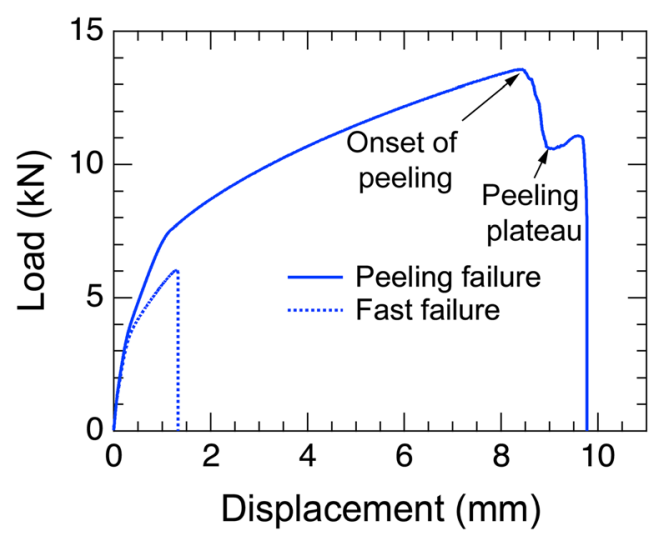

(b)

Fig. 6-Load $v s$. displacement data for samples that fail by $(a)$ base metal failure $(51 \mathrm{H}, o / t=3.7)$, peeling failure $(67 \mathrm{H}, o / t=4.1)$, and fast fracture $(67 \mathrm{~L}, o / t=0.7)$. (b) Peeling failure and fast fracture data repeated from (a) on a finer scale for clarity. Samples that failed by peeling often showed a plateau ("peeling plateau") where load briefly becomes roughly constant with displacement after the peeling crack starts to propagate.

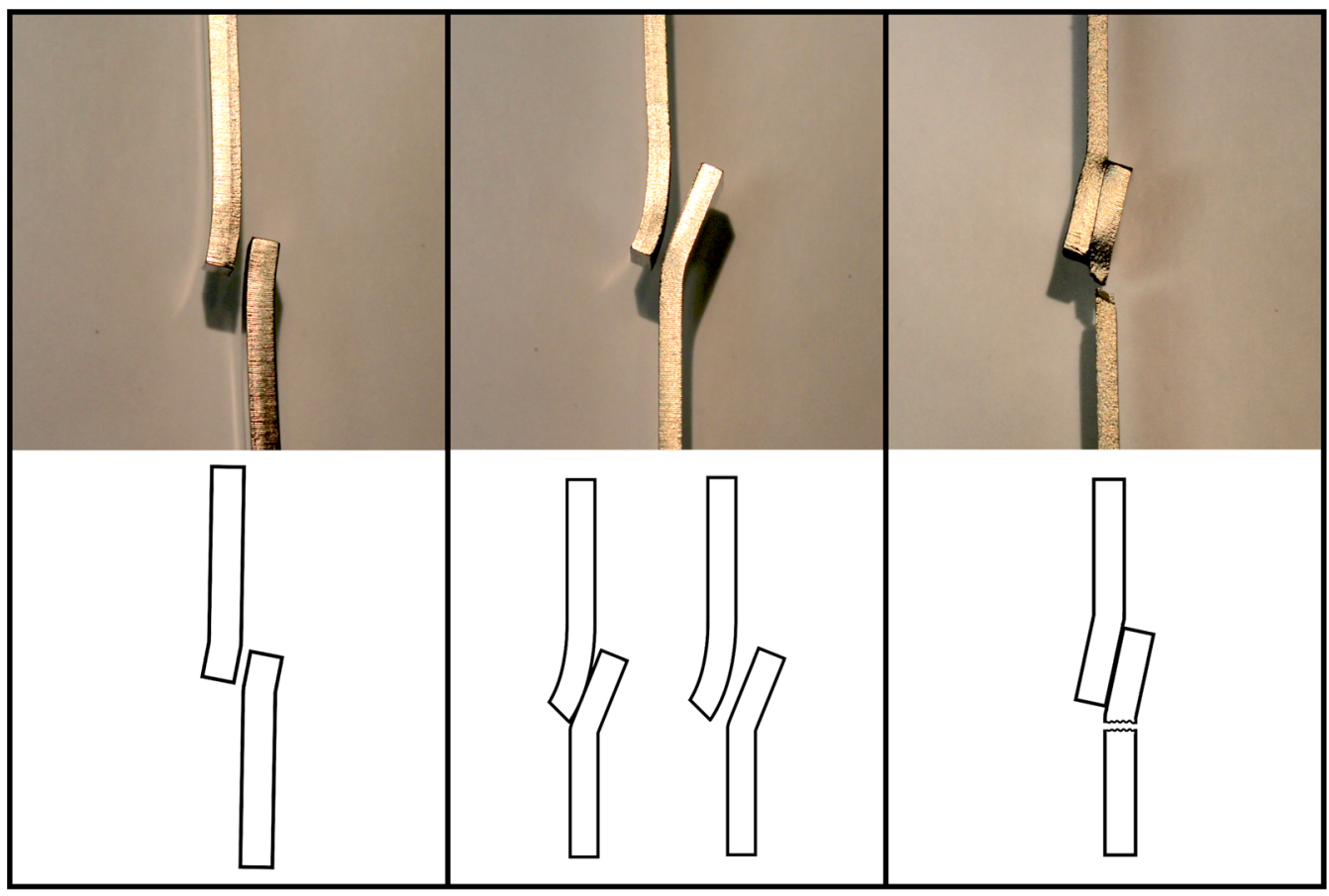

(a)

(b)

(c)

Fig. 7-Observed SLJ failure modes: $(a)$ fast fracture $(67 \mathrm{~L}, o / t=0.7),(b)$ peeling failure $(67 \mathrm{H}, o / t=4.1)$, and $(c)$ base metal failure $(51 \mathrm{H}, o / t$ $=3.7)$.

Load-displacement data from these tensile test samples were converted to engineering stress-strain. The 0.2 pct strain offset method was used to determine $\sigma_{\text {yield }}$ and the ultimate tensile strength (UTS) was determined as the maximum engineering stress during the test. The $\sigma_{\text {yield }}$ and UTS values were 341 and $663 \mathrm{MPa}$ for the as-received samples, 221 and $601 \mathrm{MPa}$ for samples exposed to Low-Cycle, and 168 and $566 \mathrm{MPa}$ for samples exposed to High-Cycle conditions, respectively. The $\sigma_{\text {yield }}$ and UTS values for the heat-treated samples are also shown in Figure 5(a).
Three distinct SLJ failure modes were observed depending on $o / t, \sigma_{\mathrm{SLJ}}, \sigma_{\text {yield }}$, and the BFM. The regions where these modes were observed are indicated in Figure 5(a) with shading. Figure 6 shows selected load-displacement data and Figure 7 representative photographs and sketches of each mode.

In the first mode, samples failed by unstable fast fracture, where a crack propagated along (or adjacent to) the braze and separated the two legs of an SLJ very rapidly (Video S-1: refer to Electronic Supplementary Material). This mode occurred in all samples when $\sigma_{\mathrm{SLJ}}$ 


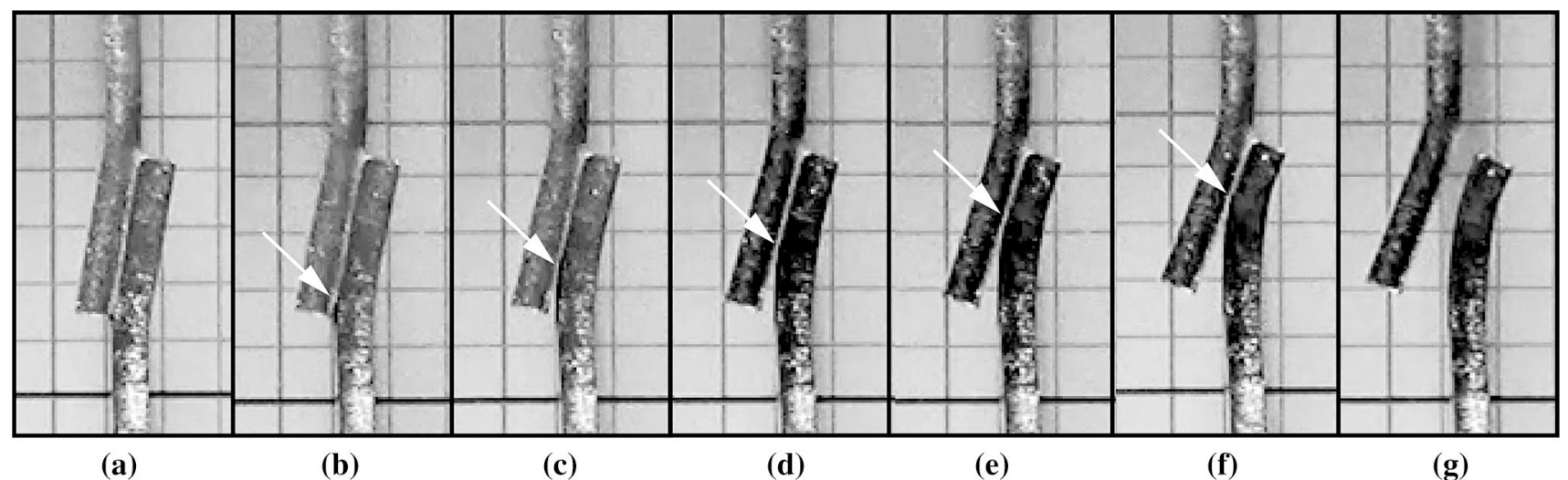

Fig. 8-Images taken sequentially at increasing test time from $(a)$ to $(g)$ showing progression of peeling failure for a $67 \mathrm{H}$ sample with $o / t=4.1$. Arrow indicates location of crack tip in each image. Background grid is $5 \mathrm{~mm}$ squares.

was below $\sigma_{\text {yield. }}$ The overall mechanical behavior of such samples was quite brittle with failure occurring suddenly at relatively low loads (Figure 6) and most showing minimal or no macroscopic plastic deformation after fracture (Figure 7(a)).

In contrast, all failures that occurred by fracture along the braze at applied loads above $\sigma_{\text {yield }}$, failed in a very different second mode where a crack (or cracks) started at one end (or both ends) of the overlap and propagated stably through the braze. A series of images showing this kind of peeling failure for a higher $o / t$ SLJ is shown in Figure 8 and Supplementary Video S-2. As the peeling crack progressed, the remaining overlap experienced additional rotation such that the crack tip remained near the plane which includes the inside face of one gauge section and the outside face of the other gauge section (Figures 8(b) through (f)). In general, when peeling occurred, a braze crack became visible and began to propagate immediately after the maximum load was reached and the load decreased as the crack grew (Figure 6(b)). Examination of the video from the $67 \mathrm{H}$ sample at $o / t=2.0$ revealed that a short braze crack had formed early in the test but did not lengthen until after the maximum load was reached. As a result, the maximum stress could not always be correlated with the first appearance of a crack. However, once the crack started to move, the load decreased. In both MBF-67 sets, which failed by peeling, for $o / t$ values $>5$, the SLJ strength reached a constant value of about $450 \mathrm{MPa}$ (Figure 5(a)).

In most samples that failed by peeling at high $o / t$, an approximately constant plateau in the load-displacement data occurred near the end of the test ("peeling plateau" in Figure 6(b)). Then, when the remaining material joining the two sample legs became small, the load again declined very rapidly as the sample failed by fast fracture. Interestingly, the applied engineering tensile stress, $\sigma_{\text {app }}$ (i.e., the applied load divided by the initial cross-sectional area of the gauge section), at each plateau, calculated from the average load during the plateau, had an average value for each system that was higher in $67 \mathrm{H}$ joints $(273 \pm 30 \mathrm{MPa})$ than in $67 \mathrm{~L}$ joints $(232 \pm 24 \mathrm{MPa})$. As can be seen in Figures 6(b), 7(a), and (b), SLJs that fail by peeling are much more macroscopically ductile than those that fail by fast fracture, undergoing more visible plastic deformation and a much slower fracture.

Peeling failures in high $o / t$ SLJs could be easily identified visually during testing or on video, but delineating between peeling and fast fracture became more difficult as $o / t$ decreased. While we define the distinction unambiguously as the difference between stable and unstable crack propagation, respectively, the final separation in all samples ultimately occurred by fast fracture. With decreasing $o / t$, the fraction of the overlap that failed by peeling decreased smoothly and continuously to zero. At some point, the time and length scales became too small for unambiguous identification of peeling from video and load-displacement data. Consequently, three indicators were used to identify the presence of peeling in low $o / t$ SLJs. First, the peeling process results in at least one leg that retains a curvature after failure due to plastic deformation in what had been the overlap region. If a single peeling crack propagates (Figure 8) the other leg remains straight in the overlap region (Figures $7(\mathrm{~b})$ and $8(\mathrm{~g})$ ). If peeling cracks propagate from both ends, both legs will be curved after failure. In contrast, for fast fracture, the final fracture surfaces will be approximately parallel to each other (Figure 7(a)). Second, the time scale for peeling was much longer. We considered samples with more than 2 seconds of data after the maximum load to have failed by peeling. Finally, it is well known that the surfaces produced by brittle fracture are considerably smoother (more reflective) than those formed by fracture processes that involve plasticity. ${ }^{[33]}$ Indeed, the portions of samples that failed by peeling are rougher and darker to the naked eye while the portions that failed by fast fracture are smoother and shinier. In higher $o / t$ samples, it was straightforward to correlate the surface features with the fracture behavior from the video recordings. Accordingly, we took the presence of similar rough dark regions as indicators of peeling in lower $o / t$ samples where peeling was difficult to distinguish from video alone. While the boundary where peeling begins is indistinct, this analysis suggests that peeling occurs for 


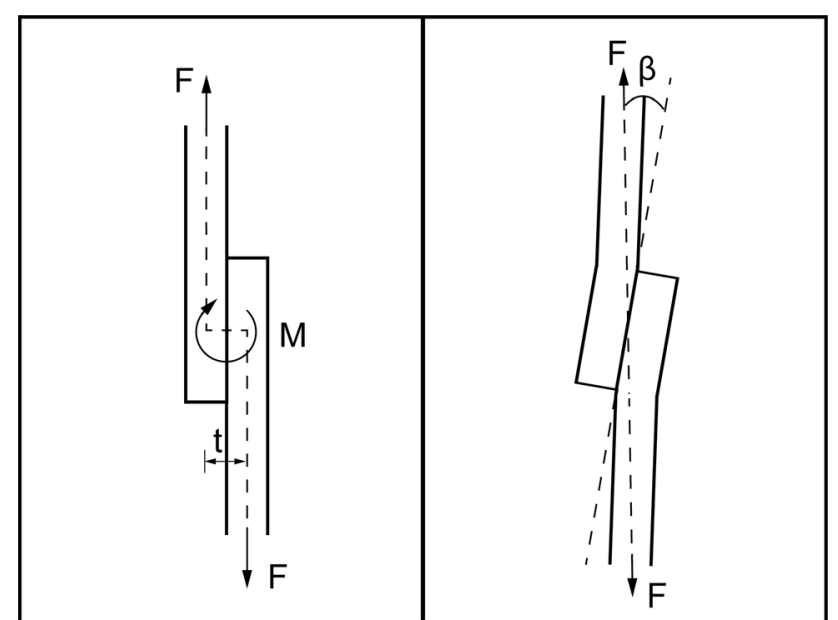

(a)

(b)

Fig. 9- (a) Eccentric loading produces a moment, which (b) leads to rotation of the braze plane by an angle $\beta$ with respect to the SLJ gauge sections.

Table II. Angle of Rotation $\beta$ Measured From Video at $\sigma_{\mathrm{SLJ}}$ and Ratio of Average Braze Tension Due to Rotation at Failure $\left(\left\langle\sigma_{\mathrm{zz}, \mathrm{R}}\right\rangle_{\text {fail }}\right)$ to SLJ Strength $\left(\sigma_{\mathrm{SLJ}}\right)$ as a Function of $o / t$ for Selected Samples

\begin{tabular}{lllllll}
\hline $51 \mathrm{H}$ & $o / t$ & 0.66 & 0.83 & 1.92 & 3.72 & 5.80 \\
& $\beta\left({ }^{\circ}\right)$ & 28 & 24 & 30 & 15 & 7 \\
& $\left\langle\sigma_{\mathrm{Zz}, \mathrm{R}}\right\rangle / \sigma_{\mathrm{SLJ}}(\mathrm{pct})$ & 71 & 49 & 26 & 7 & 2 \\
$67 \mathrm{H}$ & $o / t$ & 0.81 & 1.25 & 2.02 & 4.10 & - \\
& $\beta\left({ }^{\circ}\right)$ & 19 & 22 & 16 & 13 & - \\
& $\left\langle\sigma_{\mathrm{zz}, \mathrm{R}}\right\rangle / \sigma_{\mathrm{SLJ}}(\mathrm{pct})$ & 40 & 30 & 14 & 5 & - \\
$67 \mathrm{~L}$ & $o / t$ & 0.69 & 0.89 & 2.35 & 4.28 & - \\
& $\beta\left({ }^{\circ}\right)$ & 12 & 14 & 12 & 9 & - \\
& $\left\langle\sigma_{\mathrm{zz}, \mathrm{R}}\right\rangle / \sigma_{\mathrm{SLJ}}(\mathrm{pct})$ & 30 & 27 & 9 & 4 & - \\
\hline
\end{tabular}

$\sigma_{\mathrm{SLJ}} \gtrsim \sigma_{\text {yield }}$, so we placed the boundary at the yield stress (Figure 5(a)) for all samples.

In the third failure mode, samples failed by base metal failure, that is, a fracture across the SS base metal. This mode appears when the braze does not fail ${ }^{[3,3,6,29]}$ and therefore occurs near the ultimate tensile stress $\left(\sigma_{\mathrm{UTS}}\right)$ of the 316L SS following uniform plastic strain, strain hardening, and necking (Figures 6(a) and 7(c)). Unsurprisingly, SLJs that failed in this mode also exhibit extensive plasticity. This failure mode occurred in all but one of the $51 \mathrm{H}$ samples with $o / t>3$ (filled symbols), starting at $\sigma_{\mathrm{SLJ}}=559 \approx \mathrm{UTS}$ at $o / t \approx 4$ and increasing to $597 \mathrm{MPa}$ at $o / t \approx 12$ (Figure 5(a)). In the four cases of base metal failure shown in Figure 5(a), fracture occurred closer to the joint for medium $o / t$ SLJS and farther from the joint for high $o / t$ SLJs.

One feature that is common to all SLJ samples at all loads is bending due to misalignment of the applied longitudinal load. The initial eccentric loading shown in Figure 9(a) produces a moment that causes the overlap region to rotate, first elastically and then elastically and plastically, to align the load axes of the two SLJ gauge sections as shown in Figure 9(b). This results in bending strains in each leg that are tensile on the inside face (braze side) and compressive on the outside face, resulting in the plastic deformation seen in Figures 7 and 8 . The angle of rotation, $\beta$, between the braze plane and SLJ gauge sections (Figure 9(b)), measured at the maximum load, $\sigma_{\mathrm{SLJ}}$, from video images of selected samples, is shown in Table II. It is a strong function of the overlap ratio, base metal yield strength, and failure load. All samples have the same initial offset $(t)$ between the applied load axes, so a longer overlap requires less angular rotation to accomplish complete load axis alignment. Accordingly, the rotation at failure decreases rapidly with increasing $o / t$. At low overlap ratios and applied stresses below $\sigma_{\text {yield }}$ (Figure 5(a)), samples failed well before the gauge sections could be fully aligned.

Overall, the amount of plastic deformation in the SLJ at failure increased significantly as $o / t$ and $\sigma_{\mathrm{SLJ}}$ increased, corresponding to a transition from macroscopically brittle failure at low overlap ratios to macroscopically ductile failure at high overlap ratios. Samples that failed by peeling at high overlap ratios and all samples that failed by base metal failure underwent extensive homogeneous plastic deformation in the SLJ gauge sections prior to failure, resulting in permanent reductions in plate thickness and width that extended up to the overlap region as shown in Figure 10.

In some samples, the nominally joined area was not fully wetted by the liquid BFM. These are indicated in Figure 5 by a slash through the markers. Except for the $51 \mathrm{H}$ sample at $o / t=0.5$, these manufacturing defects had limited effect on $\sigma_{\mathrm{SLJ}}$.

\section{B. Corrosion Testing}

Corrosion test coupons consisted of two pieces of 1.6-mm (1/16 in.)-thick 316L SS with dimensions of 19 $\times 89 \mathrm{~mm}(0.75 \times 3.5$ in. $)$ and $25 \times 102 \mathrm{~mm}(1 \times 4$ in. $)$. The smaller plate was centered over the larger plate with a $38-\mathrm{mm}(0.0015$ in.)-thick amorphous brazing foil between them. This geometry encouraged the formation of braze fillets. A $0.25 \mathrm{~kg}$ weight was placed on top of the coupon before samples were vacuum furnace brazed at $10^{-5}$ Torr. The braze cycles were similar to the "Low Cycle" process shown in Figure 4 with the same heating schedule up to $850{ }^{\circ} \mathrm{C}$, including 5-minute holds at 600 ${ }^{\circ} \mathrm{C}$ and $850{ }^{\circ} \mathrm{C}$ to help ensure thermal equilibrium. In subsequent 10 minute ramps, samples made with MBF-51, MBF-67, and MBF-20 were heated to 1195 ${ }^{\circ} \mathrm{C}, 1090{ }^{\circ} \mathrm{C}$, and $1060{ }^{\circ} \mathrm{C}$, respectively, and brazed for 15 minutes before passive furnace cooling.

Brazed sample coupons were cleaned in acetone, dried, and weighed. One coupon for each BFM composition was submerged in a 25 pct phosphoric acid $\left(\mathrm{H}_{3} \mathrm{PO}_{4}\right)$ solution at $1 \mathrm{~atm}$ and $50{ }^{\circ} \mathrm{C}$ for 864 hours before being removed from the acid, cleaned, and weighed again. Similar coupons of $316 \mathrm{~L}$ SS, without being brazed, were exposed to the same solution as a control. This corrosion test follows similar work by Rabinkin et al. ${ }^{[3]}$ 


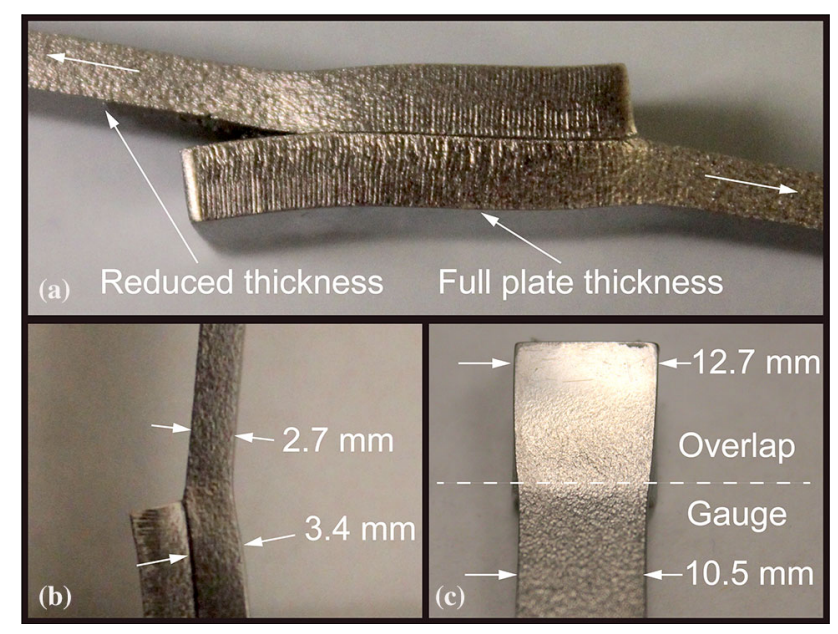

Fig. $10-$ (a) $51 \mathrm{H}$ sample with $o / t=5.8$ which peeled briefly from a wetting defect before failing in the base metal. As the crack progresses, released material on the loaded side of the joint strains and thins plastically. (b) $51 \mathrm{H}$ sample with $o / t=3.7$ that failed in the base metal showing plastic reduction in thickness and $(c)$ the same sample in top view showing plastic reduction in width in the gauge section, while the overlap region retains the original dimensions (was deformed only elastically).

The fractional mass loss in the phosphoric acid solution for braze sample coupons made from each BFM is shown in Figure 11. Samples made with MBF-67 have the best corrosion resistance, with approximately 50 pct less mass loss than those made with MBF-51 and 75 pct less mass loss than those made with MBF-20. The SS control sample had negligible mass loss.

\section{Microstructural Characterization}

$51 \mathrm{H}, 67 \mathrm{~L}$, and $67 \mathrm{H}$ samples with the same geometry as the corrosion test coupons were brazed at the same time as the SLJ samples for microstructural characterization. The brazed microstructure coupons were cross-sectioned, mounted in Lucite, and polished with a series of decreasing polishing media sizes, finishing with $0.5 \mathrm{~mm}$ diamond. Cross-sections were examined using SEM and EDX at $30 \mathrm{kV}$. Nanoindentation was used to sample the hardness of individual phases within each microstructure. Finally, fracture paths and fracture surfaces of failed SLJs were imaged to investigate the relationship between specific microstructural features and braze fracture behavior.

\section{Structure and composition}

Reactions among the constituents of the BFM and base metal during brazing result in the formation of a variety of phases in or near the braze. SEM and EDX images of representative cross-sections of the $51 \mathrm{H}, 67 \mathrm{~L}$, and $67 \mathrm{H}$ brazes are shown in Figures 12, 13, and 14, respectively. In each case, an SEM image and EDX maps showing $\mathrm{Ni}, \mathrm{Fe}$, and $\mathrm{Cr}$ concentrations in the same area are shown ( $\mathrm{Fe}$ is incorporated into the braze when a small layer of the base metal dissolves due to a reaction with the liquid BFM, a process known as "base metal

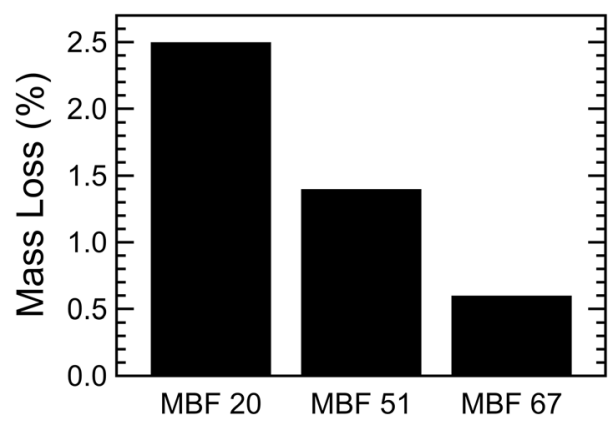

Fig. 11-Mass loss (pct) of brazed coupons after 864 hours in a 25 pct phosphoric acid $\left(\mathrm{H}_{3} \mathrm{PO}_{4}\right)$ solution at $50{ }^{\circ} \mathrm{C}$.

dissolution" ${ }^{,[6]}$. Additional maps from the same area, $\mathrm{Si}$ for MBF-51 and Mo and P for MBF-67, are also shown. $\mathrm{B}$ was not measured as EDX of light elements is not accurate (however, its behavior during Ni-based brazing of SS is well understood $d^{[3,10]}$ ). Braze boundaries were located along the line where the grain boundaries in the base metal end (see Figure 12) and where the concentrations of $\mathrm{Ni}, \mathrm{Fe}, \mathrm{Cr}$, and $\mathrm{Si}$ (for MBF-51) or $\mathrm{Ni}, \mathrm{Fe}$, and Mo (for MBF-67) show a sudden change in concentration. Note that the surfaces of the original SS plates are not perfectly planar but are 'wavy' such that the thickness of a braze varies by about $\pm 10 \mu \mathrm{m}$ over a distance of several $\mathrm{mm}$. Thus, while base metal dissolution plays an important role in determining braze thickness, the thicknesses shown in Figures 12, 13, and 14 are also affected by the local plate topography. Characteristic sizes of various microstructural features were estimated from these micrographs by measuring several examples of each to obtain average values. EDX spectra from the primary phases in each braze were analyzed using Bruker Quantax Esprit 2.1 software, the $\mathrm{P} / \mathrm{B}-\mathrm{ZAF}$ algorithm, and auto background subtract to determine approximate absolute phase compositions in normalized wt pct, which are reported in Table III. Quantitative EDX data are expected to be accurate within 1 to 3 wt pet.

The microstructures of the three sample sets are very different from one another. The $51 \mathrm{H}$ braze (Figure 12) consists solely of a single-phase Ni-Fe-Cr-Si braze matrix solid solution about $35 \mu \mathrm{m}$ thick, while the SS grain boundaries near the braze are decorated with plate-like precipitates that are rich in $\mathrm{Cr}$ and poor in $\mathrm{Fe}$ compared to the SS far field (Table III). In other work on this system (316L SS brazed with MBF-51), these grain boundary precipitates were identified as $\mathrm{Cr}_{x} \mathrm{~B}_{y}{ }^{[3]}$ Regions where $\mathrm{Cr}$ has been depleted at SS grain boundaries can be clearly seen in Figure 12(d) and are presumably the source of the $\mathrm{Cr}$ needed to form the grain boundary precipitates.

In contrast, the $67 \mathrm{~L}$ braze shown in Figure 13 is 65 $\mu \mathrm{m}$ thick and consists of a matrix solid solution phase surrounding a multiphase region that fills $\approx 49$ pct of the braze thickness. No secondary phases at SS grain boundaries are evident. The matrix phase is similar in $\mathrm{Ni}, \mathrm{Fe}$, and $\mathrm{Cr}$ contents to $51 \mathrm{H}$, but contains Mo and much less Si (Table III). The multiphase region consists of different Ni-, P-, and Cr-rich phases having a variety 


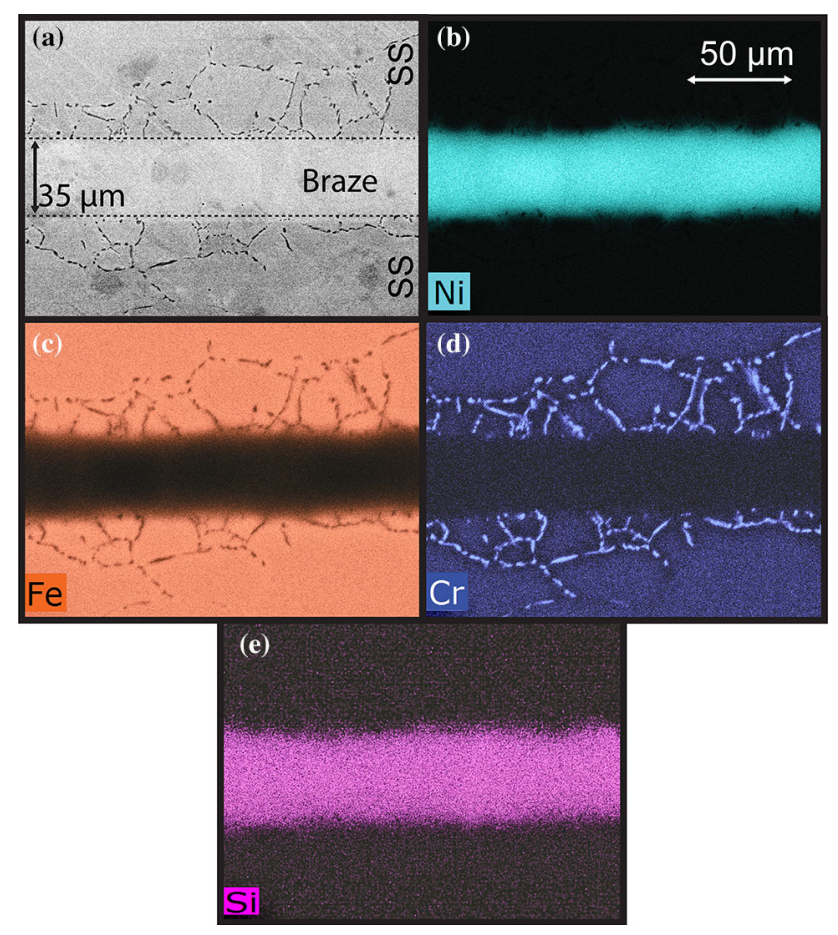

Fig. 12-(a) SEM image and (b) through (e) EDX maps showing Ni, $\mathrm{Fe}, \mathrm{Cr}$, and $\mathrm{Si}$ concentration (scales with brightness in each image independently) from the same location in a $51 \mathrm{H}$ braze joint. Dashed black lines in (a) indicate the boundary of the braze and the SS.

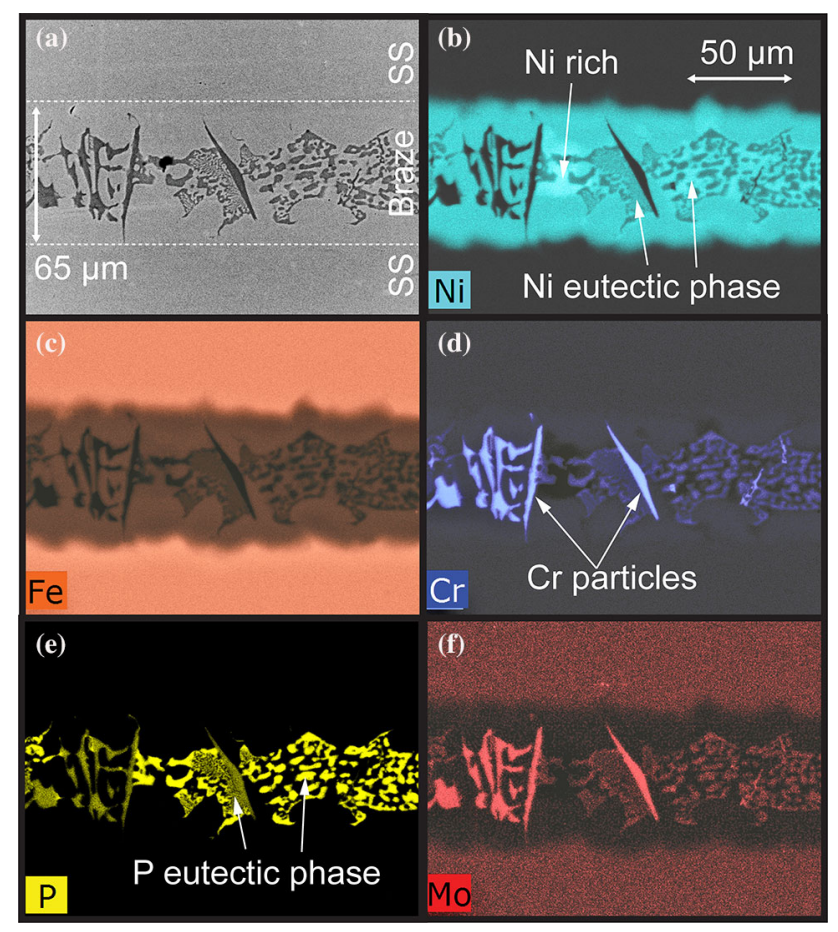

Fig. 13-(a) SEM image and (b) through $(f)$ EDX maps showing Ni, $\mathrm{Fe}, \mathrm{Cr}, \mathrm{P}$, and Mo concentration (scales with brightness in each image independently) from the same location in a $67 \mathrm{~L}$ braze joint. Dashed white lines in (a) indicate the boundary of the braze and the SS.

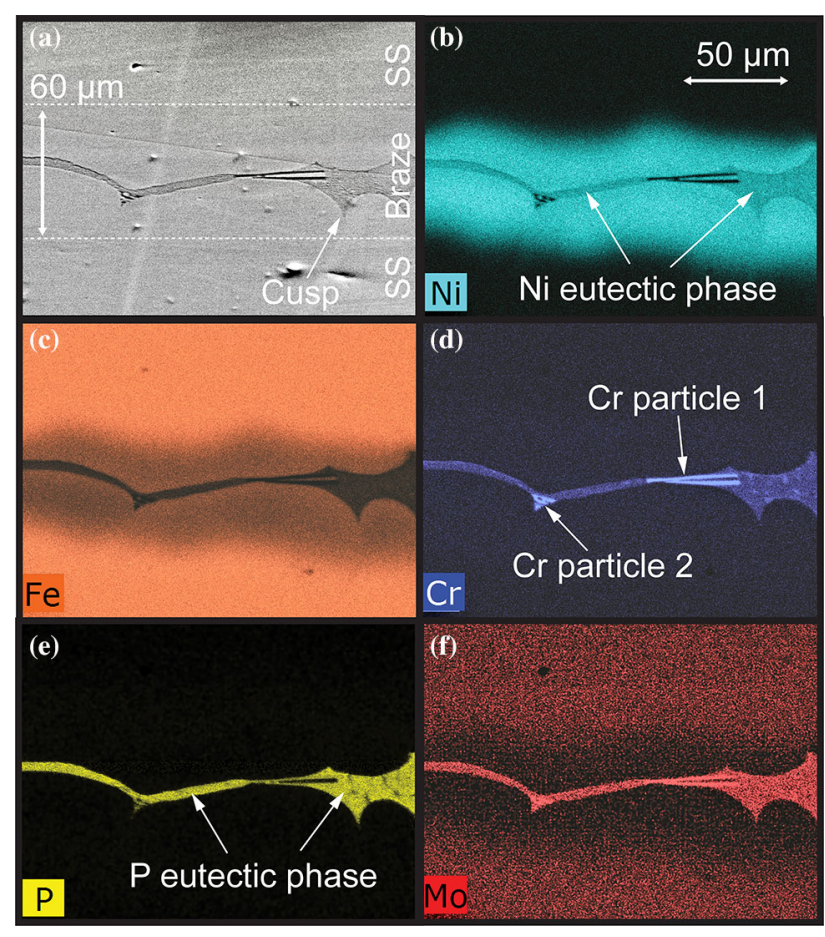

Fig. 14 (a) SEM image and (b) through ( $f$ ) EDX maps showing Ni, $\mathrm{Fe}, \mathrm{Cr}, \mathrm{P}$, and Mo concentration (scales with brightness in each image independently) from the same location in a $67 \mathrm{H}$ braze joint. Dashed white lines in (a) indicate the boundary of the braze and the SS.

of sizes and morphologies: Ni- and P-rich phases arising from a eutectic transformation (feature sizes $\sim 1$ to 3 $\mu \mathrm{m})$, and large Cr-rich particles with high aspect ratios (typically $\sim 4 \mu \mathrm{m}$ wide and up to $52 \mu \mathrm{m}$ long). These phases account for the significant decreases in $\mathrm{Cr}, \mathrm{P}$, and $\mathrm{Ni}$ in the braze matrix phase relative to the original BFM composition, in addition to base metal dissolution. The composition of the P-rich eutectic phase suggests that it is the compound $\mathrm{NiCrP}$, similar to the reports of 304 SS brazed with a Ni-Cr-Si-P BFM. ${ }^{[6]}$

The $67 \mathrm{H}$ braze shown in Figure 14 is quite different from the $67 \mathrm{~L}$ braze. It is $60 \mu \mathrm{m}$ thick and, as with $67 \mathrm{~L}$, consists of a matrix phase surrounding a multiphase region and no secondary phases at SS grain boundaries. However, the multiphase region in the $67 \mathrm{H}$ sample fills much less of the braze $(\approx 12 \mathrm{pct})$ than in $67 \mathrm{~L}$. The braze matrix also contains significantly less $\mathrm{Ni}$ and more $\mathrm{Fe}$ than either $51 \mathrm{H}$ or $67 \mathrm{~L}$ and similar amounts of $\mathrm{Cr}$, Mo, and $\mathrm{Si}$ to $67 \mathrm{~L}$. The multiphase region has a characteristic cusp morphology (cusp formation is described in Reference 6) which consists of much finer Ni-rich (Figure 14(b)) and P-rich (Figure 14(e)) phases (feature sizes $\sim 0.7 \mu \mathrm{m})$ than in $67 \mathrm{~L}$, as well as a few large Cr-rich particles with widely varying morphology (from roughly equiaxed, e.g., $8 \mu \mathrm{m} \times 10 \mu \mathrm{m}$, to plate shaped, e.g., $5 \mu \mathrm{m}$ $\times 40 \mu \mathrm{m}$ as seen in Figure 14(d)). Higher Fe concentrations and lower $\mathrm{Ni}, \mathrm{Cr}$, and $\mathrm{P}$ concentrations in the $67 \mathrm{H}$ phases show that significantly more diffusional interchange between the braze and base metal has occurred in the $67 \mathrm{H}$ sample than in the $67 \mathrm{~L}$ sample. 
The plate surfaces had a slight curvature within a few hundred micrometers of plate ends leading to a thicker braze and curved braze surfaces at overlap ends (i.e., braze fillets). Examples of these braze fillets and their microstructures for each of the three sample sets are shown in Figure 15. Although the $51 \mathrm{H}$ braze is single phase where it is thin (Figure 12), the $51 \mathrm{H}$ braze fillet contains plate-like particles, likely $\mathrm{Cr}_{x} \mathrm{~B}_{y}$, which appear and increase in size as the braze thickness increases and sufficient $\mathrm{B}$ is no longer able to diffuse out of the braze (Figure 15(a)). The average dimensions of these particles are $21 \mu \mathrm{m}$ long by $2 \mu \mathrm{m}$ wide. Despite the fact that the braze microstructures of $67 \mathrm{~L}$ and $67 \mathrm{H}$ are very different (Figures 13 and 14), the braze fillet microstructures in these samples are very similar (Figures 15(b) and (c)). Both are comprised of matrix solid solutions surrounding large multiphase regions containing very fine eutectic structures $\sim 1 \mu \mathrm{m}$ thick.

\section{Hardness}

Nanoindentation was used to determine the hardness of individual phases in all three samples. A second set of cross-sections from the microstructure coupons were

Table III. Composition of Phases in 51H, 67L, 67H, and 316L SS as Measured by EDX (Estimated Accuracy 1 to 3 Pct) (See Figs. 12, 13, and 14)

\begin{tabular}{llrrrrrr}
\hline & Phase (Norm Mass Pct) & $\mathrm{Ni}$ & $\mathrm{Fe}$ & $\mathrm{Cr}$ & $\mathrm{Mo}$ & $\mathrm{Si}$ & $\mathrm{P}$ \\
\hline \multirow{5}{5}{$1 \mathrm{H}$} & matrix solid solution & 49 & 28 & 17 & - & 5 & - \\
& GB precipitates & 2 & 57 & 41 & - & 0 & - \\
$67 \mathrm{~L}$ & matrix solid solution & 52 & 24 & 21 & 1 & 1 & 0 \\
& Ni-rich eutectic phase & 58 & 22 & 17 & 1 & 1 & 1 \\
& P-rich eutectic phase & 35 & 10 & 33 & 1 & 0 & 20 \\
& Cr-rich particles & 4 & 6 & 76 & 5 & 0 & 9 \\
& Ni-rich phase & 65 & 22 & 12 & 0 & 1 & 0 \\
$67 \mathrm{H}$ & matrix solid solution & 35 & 44 & 19 & 1 & 1 & 0 \\
& fine eutectic average & 28 & 34 & 25 & 4 & 1 & 9 \\
& Cr-rich particle 1 & 10 & 22 & 53 & 8 & 0 & 7 \\
& Cr-rich particle 2 & 23 & 34 & 33 & 5 & 1 & 4 \\
SS & far field & 9 & 70 & 18 & 2 & 0 & - \\
\hline
\end{tabular}

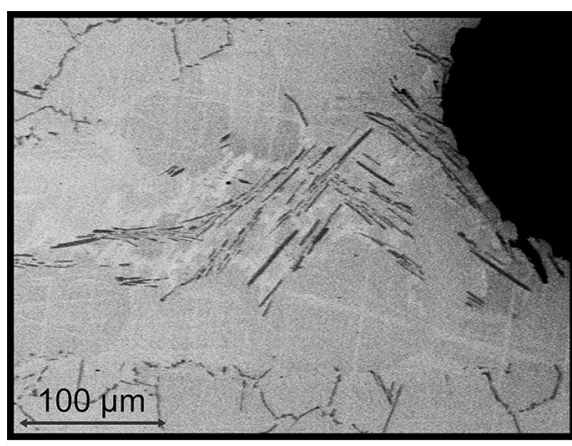

(a) MBF-51 High Cycle polished with a series of decreasing media size $\mathrm{SiC}$ sandpapers before finishing with an $0.03 \mathrm{~mm} \mathrm{Al}_{2} \mathrm{O}_{3}$ slurry. Indentation experiments were performed with a Hysitron TI-900 Triboindenter using a Berkovich tip with $120 \mathrm{~nm}$ tip radius. Indentations were made by ramping up the load at $2 \mathrm{mN} / \mathrm{s}$, holding at a maximum load of $10 \mathrm{mN}$ for 10 seconds, and then unloading at 2 $\mathrm{mN} / \mathrm{s}$. A row of 100 indentations was made along a line at a shallow angle to the braze plane to sample the hardness across the thickness of each braze. Each indentation was placed $10 \mu \mathrm{m}$ horizontally and $1 \mathrm{~mm}$ vertically from the previous indent as shown in Figures 16(a) through (c). Each line of indents begins in the SS, traverses the braze, and ends in the SS (verified by EDX).

Hardness was calculated from load-displacement data using the Oliver and Pharr method ${ }^{[32]}$ Calculated contact depths were 100 to $350 \mathrm{~nm}$ and the diameters of the residual indents were 0.7 to $2.4 \mathrm{~mm}$. Hardness values as a function of distance across the braze thickness are shown in Figures 16(d) through (f). For all samples, the hardnesses of the braze matrix solid solution and the SS just outside the braze are the same. For $51 \mathrm{H}$ (Figure 16(d)), the four higher values arose from hitting $\mathrm{Cr}_{x} \mathrm{~B}_{y}$ precipitates at $\mathrm{SS}$ grain boundaries. For $67 \mathrm{~L}$ and $67 \mathrm{H}$ (Figures 16(e) and (f)), the higher values arose from hitting hard second-phase particles in the multiphase regions.

While a detailed phase analysis is beyond the scope of this study, both compositional analysis (Table III) and hardness results (Figure 16) show that there are a variety of hard particles in these microstructures, and suggest that many are IMCs (e.g., $\mathrm{Cr}_{x} \mathrm{~B}_{y}$ and $\mathrm{NiCrP}$ ). The hardnesses of the matrix and particles in MBF-67 (Figures 16(e) and (f)) compare closely to results for a similar system. ${ }^{[6]}$

\section{Fracture paths and fracture surfaces}

The fracture pathways of failed SLJs are shown in cross-section in Figure 17. Figure 17(a) shows a $51 \mathrm{H}$ sample with $o / t=2$ that failed by peeling. In this case, the fracture occurred along the $\mathrm{Cr}_{x} \mathrm{~B}_{y}$ precipitates at SS grain boundaries outside the braze. Figures 17(b) and c show $67 \mathrm{~L}$ and $67 \mathrm{H}$ samples, respectively, both with $o / t$

Fig. 15-Braze fillets of $(a) 51 \mathrm{H},(b) 67 \mathrm{~L}$, and (c) 67H showing the 3-D geometry, and subsequently different microstructures, of braze fillets in contrast to the 2-D planar geometry (Figs. 12, 13, and 14). 


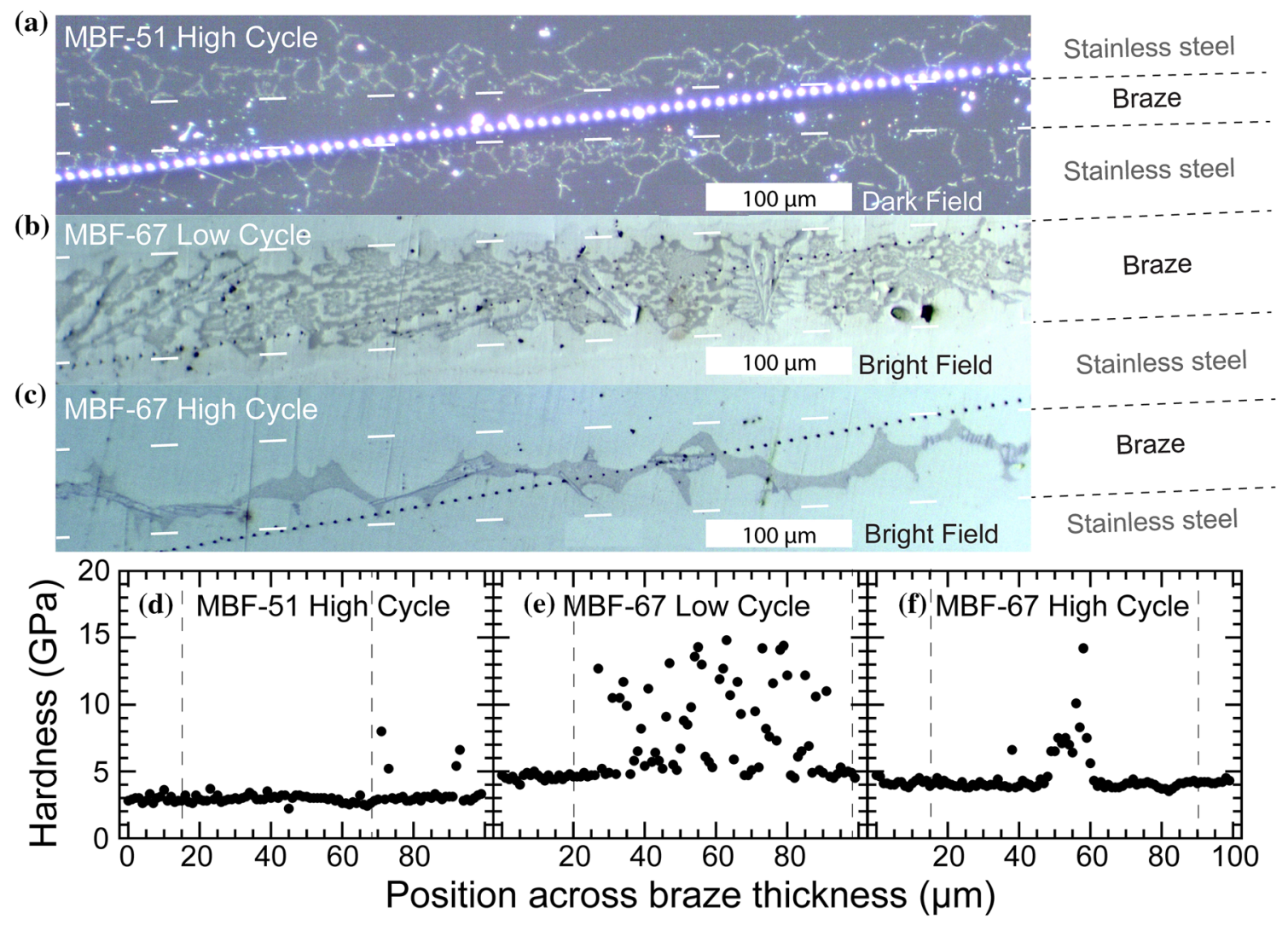

Fig. 16-(a) Dark-field, and (b) and (c) bright-field light microscopy images of nanoindentations across the braze thickness (dashed lines indicate the boundary between the braze and the stainless steel). (d) through $(f)$ Hardness of braze phases as a function of position across the braze thickness. In all cases, the hardness of the matrix phase is similar to that of the stainless steel, while the Cr- and/or P-rich phases show significantly higher hardness.

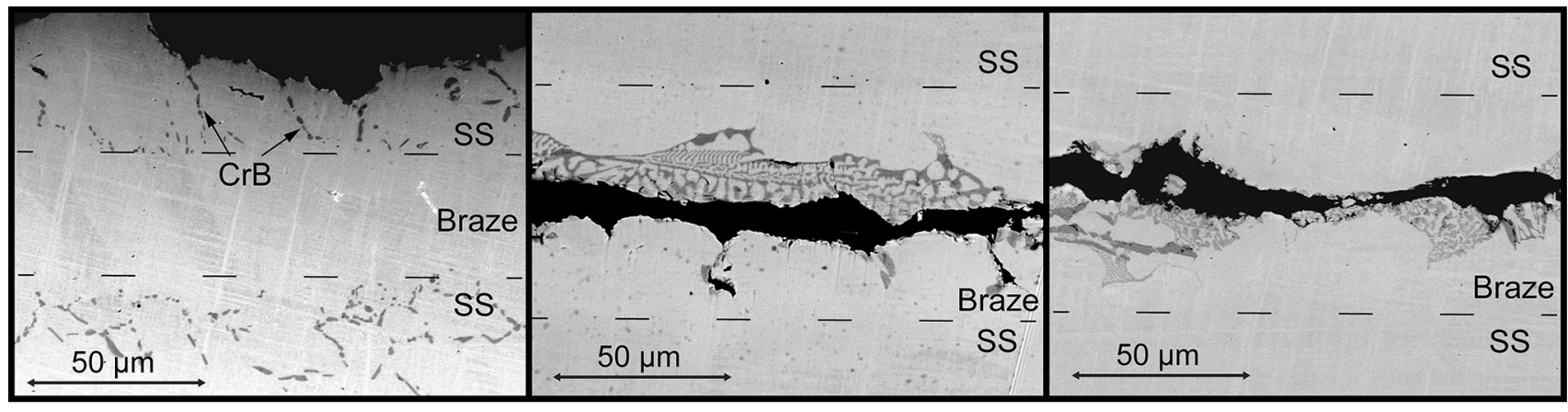

(a) MBF-51 High Cycle

(b) MBF-67 Low Cycle

(c) MBF-67 High Cycle

Fig. 17-SEM images of fractured SLJs in cross-section. Dashed lines indicate the interface between the braze and the stainless steel. 51H (a) failed in the base metal adjacent to the braze (in the region with $\mathrm{Cr}_{x} \mathrm{~B}_{y}$ particles at grain boundaries). $67 \mathrm{~L}(b)$ and $67 \mathrm{H}(c)$ failed in the multiphase region along the braze centerline.

$=4$. These samples were peeling when the test was stopped before failure. In both cases, the fracture follows a chaotic path within the multiphase region.

The fracture surfaces of $67 \mathrm{H}$ and $67 \mathrm{~L}$ samples were also examined in plan view using EDX at $25 \mathrm{kV}$. Cr EDX maps of peeling braze fracture surfaces $(o / t=4)$ in Figure 18 reveal large numbers of high-aspect-ratio Cr-rich particles on both 67L (Figure 18(a)) and $67 \mathrm{H}$ (Figure 18(b)) fracture surfaces. The $67 \mathrm{H} \mathrm{Cr-rich}$ particles are much closer together while the $67 \mathrm{~L} \mathrm{Cr}$-rich particles have higher aspect ratios.

\section{DISCUSSION}

A detailed examination of the above results provides insights in three areas: 


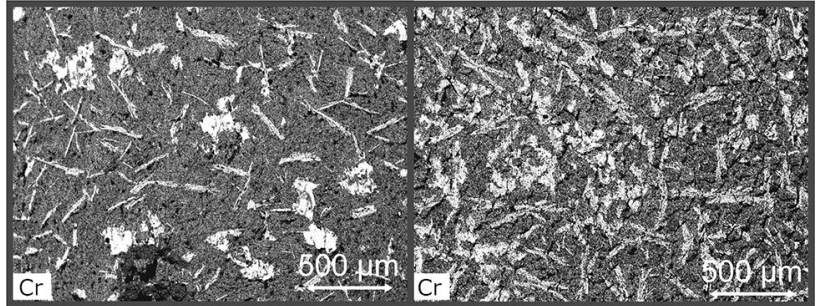

(a) MBF-67 Low Cycle

(b) MBF-67 High Cycle

Fig. 18 - Cr EDX maps, with individually scaled intensity, of $(a)$ $67 \mathrm{~L}$ and $(b) 67 \mathrm{H} \mathrm{SLJ}$ fracture surfaces. Cr particles in $67 \mathrm{H} \mathrm{(b)} \mathrm{are}$ significantly closer together than in $67 \mathrm{~L}$ (a).

First, when brazing 316L stainless steel (SS), switching from the "corrosion-resistant" MBF-51 to the "very corrosion-resistant" MBF-67, significantly reduces the corrosion rate $(\approx 57 \mathrm{pct})$ in exchange for a modest $(\approx 22$ pct) decrease in joint strength. At a coarse level of analysis, both of these trends are consistent with conventional interpretations. That is, as brazing filler metal (BFM) $\mathrm{Cr}$ content increases and $\mathrm{B}$ content decreases, corrosion resistance increases due to a higher concentration and more uniform distribution of $\mathrm{Cr}$ while as $\mathrm{Cr}$ and $\mathrm{P}$ content increase, the joint strength decreases due to an increasing number of hard brittle particles that are increasingly spatially connected.

Second, a detailed analysis of the mechanical deformation and failure modes suggests that the strength of brazed single-lap joints (SLJs) is much more complicated than typical interpretations-particularly simplified explanations that focus on average braze shear stress $\left(\tau_{\text {SLJ }}\right)$ - allow. We find that, for all samples, the failure mode varies from brittle fast fracture in the braze for low overlap ratios to ductile peeling failure in the braze at higher overlap ratios. In some cases, but not all, the failure mode shifts again to base metal failure at even higher overlap ratios. We show that both the failure mode and the SLJ strength depend on three interrelated quantities:

- joint geometry - which plays a primary role in determining the stress distribution (following AWS C3.2, ${ }^{[14]}$ overlap length is the primary variable and in the present study, $\sigma_{\mathrm{SLJ}}$ depends more strongly on overlap ratio than on choice of BFM or braze cycle),

- base metal properties-particularly yield strength and strain hardening, which determine how the geometry and stress state evolve with load, and

- braze and braze fillet microstructure-particularly resistance to fracture initiation and propagation.

Third, our attempt to improve the mechanical properties of joints brazed with MBF-67 by increasing the time and temperature of the braze cycle was only partially successful. The braze microstructure was indeed substantially modified (compare Figures 13 and 14, 16(b) and (c), 17(b) and (c), and 18(a) and (b)), and the SLJ strength was significantly improved, but only at low overlap ratios (Figure 5(a)). At high overlap ratios, the SLJ strength was unaffected.
We consider failure to be controlled in the conventional way by crack initiation and propagation when $K=Y \sigma \sqrt{c} \geq K_{c}$, where $K$ is the stress intensity factor, $\sigma$ the magnitude of the relevant stress, $c$ a critical "flaw" (or crack) size, $Y$ a constant dependent on geometry, and $K_{c}$ the critical value to initiate crack motion (a local materials property). ${ }^{[33]}$ We have both highly inhomogeneous stress states and highly inhomogeneous microstructures; therefore, we assume that failure occurs when a sufficiently high local stress and a microstructural feature that can act as a flaw leading to fracture are collocated.

In the following, we describe how both the joint geometry and the stress state evolve with load and show how these interact with base metal properties and braze and braze fillet microstructures to determine the failure mode and the SLJ strength. Along the way, we explain the results of our attempt to improve mechanical properties by modifying the braze cycle, discuss improved practices for evaluating and reporting the strength of brazed SLJs, and suggest specific modifications to the AWS C3.2 standard. Finally, we briefly explain the corrosion results in terms of the microstructure.

\section{A. SLJ Stress State}

If the stress distribution is inhomogeneous, the failure load is determined by the peak stress, not the average stress. The stress distribution in SLJs is well known to be inhomogeneous ${ }^{[13,15-19,23-28,30,31,34-39]}$; therefore, to understand the failure modes of brazed SLJs, it is necessary to understand the stress state.

For brazed SLJs, only a few analyses have been reported in which the actual inhomogeneous stress states have been analyzed or utilized to interpret joint strength. ${ }^{[16,17,19,24-26]}$ Instead, joint strength for brazed joints is typically described in terms of the average values, $\sigma_{\mathrm{SLJ}}$ and $\tau_{\mathrm{SLJ}}($ e.g., References $3-5,13,14,18,20$, and 29). Similar reporting practices are also found for brazed double-lap joints ${ }^{21]}$ and modified SLJs. ${ }^{[15,22]}$ Even when it is acknowledged that the stress state is inhomogeneous, average values $\left(\sigma_{\mathrm{SLJ}}\right.$ and $\left.\tau_{\mathrm{SLJ}}\right)$ are still commonly reported ${ }^{[13,16,17,19,25,26]}$ _-perhaps due to the fact that AWS C3.2 specifies only these values to be reported.

In contrast, the actual inhomogeneous stress states and their consequences have been extensively studied in SLJs joined with polymer adhesives ("adhesive SLJs"), e.g., References 23, 27, 28, 30, 31, and 34-39. The adhesive in adhesive SLJs is typically much thicker $(\sim 4$ to $20 \times)$ and much more compliant $(\sim 50 \times)$ than the braze in a brazed SLJ. Despite this, the stress states in adhesive SLJs are expected to be qualitatively similar to those in brazed SLJs and experimentation on and modeling of adhesive SLJs can provide insights into the stress distribution and failure behavior of brazed SLJs.

In particular, as the adhesive becomes very thin, the stress state in an adhesive SLJ approaches that of a brazed SLJ and several groups, e.g., References 23, 27, 
28, and 38, have used model "monolithic SLJs" (i.e., samples with the geometry of Figure 2(b) but cut out of a single monolithic block with no interface) to study stress states in SLJs (at least one such work was motivated by brazing ${ }^{[24]}$. A monolithic SLJ represents an upper limit on SLJ strength and, to the extent that the braze and the base metal have similar properties (i.e., most brazed SLJs), should have a stress state that is quantitatively very similar to that in a brazed SLJ.

The stress states in SLJs are complex and have no simple closed form solutions. Simplified 2-D linear elastic numerical models provide initial guidance, ${ }^{[23,31,34]}$ while 2-D finite element analysis (FEA) has been used to consider plasticity in flexible adhesive, ${ }^{[36,38]}$ brazed, ${ }^{[17]}$ and monolithic ${ }^{[26]}$ SLJs. A detailed 3-D FEA that includes plasticity would be necessary for a complete description, but this is rare in adhesive $\mathrm{SLJ}_{\mathrm{S}}{ }^{[30]}$ and entirely absent for both brazed and monolithic SLJs.

Here we provide a qualitative description of the stress state adequate for interpreting brazed SLJ failure modes. For simplicity, we consider a monolithic SLJ and analyze the stresses both along the "interface" where the braze would be in a brazed SLJ (which we refer to simply as "braze" from now on) and within the SLJ legs (Figure 2). It is convenient to describe the SLJ stress state in terms of a shear-lag stress distribution with modifications due to overlap rotation.

\section{Shear-lag stress distributions}

Shear-lag stress states are common and occur whenever a loaded body subjected to uniaxial stress along its length transfers load to a discontinuous adjacent parallel body by shear. Examples include plate-reinforced concrete beams ${ }^{[40]}$ and thin plates on thick substrates subjected to differential thermal expansion. ${ }^{[41]}$ To consider shear-lag separate from the stresses that arise due to overlap rotation, we consider a hypothetical SLJ that is reasonably long and does not rotate $(\beta=0)$.

a. Stresses due to longitudinal shear-lag The stress state due to shear-lag is illustrated in Figure 19. We introduce a coordinate system where $x$ is the longitudinal direction, $y$ the width or transverse direction, and $z$ the thickness direction (Figure 19(a)). Moving from left to right along a horizontal line in the upper leg, the longitudinal normal stress $\left(\sigma_{x x}\right)$ at the overlap end must begin at zero at the free surface and increase to the full applied stress at the opposite overlap end (Figure 19(b)). A shear stress, $\tau_{x z}$, must arise along the braze to transfer the longitudinal load between the two legs of the SLJ. This shear stress must be zero at the free surface, rise quickly as load is transferred from one leg to the other, and decay to zero in the middle of the overlap as the longitudinal normal stress becomes the same at half of the applied stress $\left(\sigma_{\text {app }} / 2\right)$ in both legs (Figure 19(c)).

The variations in $\sigma_{x x}$ and $\tau_{x z}$ along the overlap length require normal stresses perpendicular to the braze to satisfy equilibrium. In general, we refer to a $\sigma_{z z}$ stress component as "braze normal stress" (sometimes called "peel stress"[17,38] or "tearing stress"[16,23]). The braze normal stress due to the longitudinal loading, $\sigma_{\mathrm{zz}, \mathrm{L}}$, has (a)

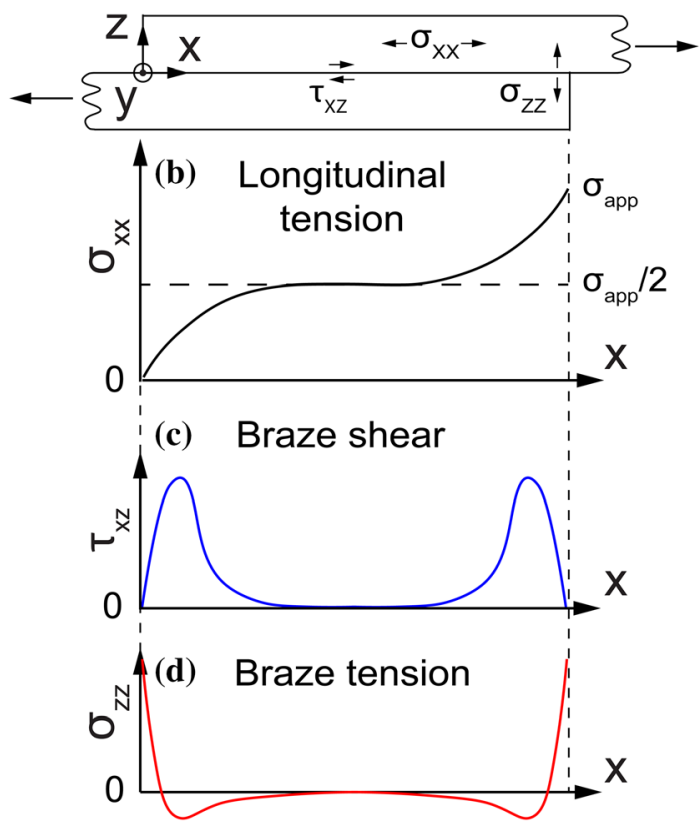

Fig. 19-(a) Schematic of SLJ showing qualitative shear-lag stress distributions for $(b)$ longitudinal normal stress, $\sigma_{x x}$, in the top leg, (c) shear stress along the braze, $\tau_{x z}$, and (d) normal stress, $\sigma_{z z}$, perpendicular to the braze (following Goland and Reissner ${ }^{[23]}$ ).

large tensile peaks near overlap ends followed by broader and shallower compressive stresses (necessary since the net force in the $z$ direction must be zero as long as $\beta=0$ ) further away from the ends (Figure 19(d)).

The stress gradients (Figure 19) die off with distance from overlap ends at a rate determined by the material properties and thicknesses of both the base metal and the braze. Elastic calculations ${ }^{[23,41]}$ suggest that, for typical brazes, the load is essentially fully transferred to both sides of the overlap (uniform longitudinal stresses in both legs) within a few plate thicknesses $t$ of each end, while stresses along the braze die off much more quickly, within $<2 t$.

The stress concentrations associated with the braze shear (Figure 19(c)) and braze normal (Figure 19(d)) components due to longitudinal shear-lag can be quite high. Goland and Reissner's elastic plane-strain calculations for a monolithic SLJ give peak stresses along the braze of $\tau_{x z}=0.79 \sigma_{\text {app }}$ and $\sigma_{\mathrm{zz}, \mathrm{L}}=4.3 \sigma_{\mathrm{app}}{ }^{[23]}$ for a sample with no rotation (see Section III-A-ii for effects of rotation). Calculations for the stress distributions arising from differential thermal expansion at the interface of a thin plate bonded to a thick substrate give very similar results. ${ }^{[41]}$ Note that plasticity in and near the braze would both limit the peak stresses due to shear-lag and cause the stress distributions to widen.

b. Stresses due to transverse shear-lag As the SLJ legs far from the overlap undergo longitudinal strain, they contract in the transverse $(y)$ direction due to Poisson effects at low loads and isochoric plasticity at higher loads. Just inside the overlap, the loaded plate (e.g., the top leg at the right side of the overlap in Figure 19(b)) 
carries the full longitudinal load and would contract in the transverse direction, but is constrained by the unloaded leg to which it is bonded. This results in additional shear-lag stress distributions in the transverse direction at overlap ends including transverse shear stress $\left(\tau_{y z}\right)$ in the braze and normal $\left(\sigma_{y y}\right)$ stress in the plate, as well as additional braze normal stress $\left(\sigma_{\mathrm{zz}, \mathrm{T}}\right)$. The forms of the variations in $\tau_{y z}$ and $\sigma_{\mathrm{zz}, \mathrm{T}}$ with $y$ are similar to the variations in the corresponding longitudinal components shown in Figures 19(c) and (d), except that the shear stresses have opposite signs near the opposing faces in the width direction. $\sigma_{y y}$ must be zero at those same faces, rising to a maximum at the sample centerline.

As with the longitudinal shear-lag components, for elastic deformation, the stress gradients associated with transverse shear-lag die out within a few plate thicknesses $(<2 t$ at the braze) of the transverse faces making the stress distribution width-dependent. These stresses are not insignificant. As discussed for flexible adhesive SLJs, ${ }^{[35]}$ assuming a sufficiently wide sample, elastic deformation, and that the differential strain is accommodated equally in the SLJ legs, the maximum transverse normal stress is $\sigma_{y y}=v \sigma_{x x} / 2$. To the extent that the transverse and longitudinal shear distributions have the same form, the peak shear stress would be $\tau_{y z}=$ $v \tau_{x z}$. It is reasonable to assume that the maximum value of $\sigma_{\mathrm{zz}, \mathrm{T}}$ lies in the range $v \sigma_{\mathrm{zz}, \mathrm{L}} / 2<\sigma_{\mathrm{zz}, \mathrm{T}}<v \sigma_{\mathrm{zz}, \mathrm{L}}$. Note that, when the gauge section deforms plastically, the differential in average transverse strain in the $y$ direction between the loaded and unloaded leg at overlap ends increases further, increasing the transverse shear-lag stress concentrations.

The net effect of longitudinal and transverse shear-lag is that the stresses on the braze are concentrated near overlap ends with the highest stresses appearing near overlap corners (at least for wide overlaps).

\section{Stresses due to overlap rotation}

As described in Section II-A, the offset loading of the SLJ geometry leads to overlap rotation (Figure 9; Table II). This rotation magnifies the shear-lag stresses described previously and causes the SLJ test to be geometrically nonlinear-i.e., it significantly modifies the stress distribution in the sample as the load increases. It is reasonable to describe the stress state as one of shear-lag at very low stress (rotation is zero when $\sigma_{\text {app }}=0$ ) that is modified by rotation as the test proceeds. The amount of rotation at a given load is a strong function of the overlap ratio, gauge section length, configuration of the sample grips, and base metal yield strength and strain hardening characteristics, so quantitative generalizations are elusive. Nonetheless, overlap rotation affects the stress state in an SLJ in three ways:

a. Bending stresses First, as discussed in Section II-A, overlap rotation leads to bending strains in each leg at overlap ends that are tensile on the inside (braze) faces and compressive on the outside faces. Inside the overlap, the tensile bending strains increase the magnitudes of the stress peaks that arise due to shear-lag. We define the joint stress concentration as the ratio of the maximum stress in the braze to the applied engineering tensile stress, $\sigma_{\text {app }}$. Because of joint rotation, the magnitude of the maximum normal and shear stresses in the braze increase with increasing load; although, because the bending moment decreases as rotation increases, ${ }^{[23,28,37]}$ the rate of rotation, and thus the joint stress concentration, decreases with increasing load. Outside the overlap, overlap rotation leads to localized plastic deformation that begins on the inside face just outside the overlap and greatly facilitates further rotation by the formation of a plastic hinge (Figures 7(b) and (c), 8, and 10(a) and (b)).

b. Stress redistribution due to load axis angle change Second, as overlap rotation changes the angle $\beta$ between the braze plane and the load axis (Figure 9; Table II), it changes the stress distribution along the braze. For a monolithic SLJ at a given applied load, increasing $\beta$ causes the shear-lag stress peaks to become lower but wider, distributing the stresses more uniformly along the braze. ${ }^{[27]}$ Note that the maximum stresses in the braze nonetheless continue to increase with load although the stress redistribution due to rotation reduces the rate at which they increase. Also, since a component of the load is now perpendicular to the braze, a tensile braze normal stress, $\sigma_{\mathrm{zz}, \mathrm{R}}$, arises. Although this stress is not uniformly distributed, its average value at failure is $\left\langle\sigma_{\mathrm{zz}, \mathrm{R}}\right\rangle_{\text {fail }}=\sigma_{\mathrm{SLJ}} \times w t \times$ $\sin (\beta) / o w$. This value, normalized by $\sigma_{\mathrm{SLJ}}$, is shown in Table II. Because both $\beta$ and the area $o w$ vary with $o / t$, $\sigma_{\mathrm{zz}, \mathrm{R}}$ and $\left\langle\sigma_{\mathrm{zz}, \mathrm{R}}\right\rangle_{\text {fail }}$ are strongly dependent on $o / t$. It is useful to note that the ratio of the maximum to the minimum stress in the braze therefore decreases as rotation increases because the minimum stress becomes nonzero.

c. Stresses due to anticlastic curvature Third, samples may adopt anticlastic curvatures in the SLJ legs outside the overlap due to Poisson effects in response to the bending associated with overlap rotation. Just inside the overlap, this anticlastic curvature is resisted by the unloaded leg, leading to yet an additional contribution to the braze normal stress, $\sigma_{\mathrm{zz}, \mathrm{A}}$. While anticlastic curvature has been mentioned with respect to adhesive joints, ${ }^{[31]}$ we are not aware of any analyses that explicitly account for it in brazed SLJs. Nevertheless, it increases the braze stress at the overlap ends increasing the joint stress concentration.

\section{Effect of overlap length}

The overall stress state in an SLJ varies dramatically with overlap length leading to significant changes in failure mode and SLJ strength. These changes are primarily due to sample rotation, although interactions between the shear-lag stress concentrations and the reduction in braze area also play a role at low overlap ratios.

At high overlap ratios, rotations are small (Table II) and the stress state immediately prior to failure 
approximates the shear-lag form shown in Figure $19-$ modified by plasticity and whatever small rotation occurs. The shear $\left(\tau_{x z}\right)$ and normal $\left(\sigma_{z z}=\sigma_{\mathrm{zz}, \mathrm{L}}\right.$ $\left.+\sigma_{\mathrm{zz}, \mathrm{T}}+\sigma_{\mathrm{zz}, \mathrm{R}}+\sigma_{\mathrm{zz}, \mathrm{A}}\right)$ stresses on the braze are highly concentrated at the ends of the overlap, while in the middle of the overlap the stresses on the braze approach zero $\left(\tau_{x z}=\sigma_{z z}=\tau_{y z}=0\right)$ and the longitudinal stress becomes uniform at $\sigma_{x x} \approx \sigma_{\text {app }} / 2$ through the thickness in both legs. At high $o / t$, the stress state, and thus $\sigma_{\mathrm{SLJ}}$, is insensitive to overlap length; as $o / t$ changes in this region, the stress concentrations simply move closer together or farther apart without a significant change in magnitude or distribution. In our samples, $\sigma_{\mathrm{SLJ}}$ becomes nearly independent of $o / t$ for MBF-67 SLJs with $o / t \gtrsim$ 6 , indicating that the stress state is not changing substantially.

As $o / t$ decreases, the rotation at a given load increases, ${ }^{[23,28,37,38]}$ increasing the bending strains at the overlap ends and thus the maximum braze stresses, causing $\sigma_{\mathrm{SLJ}}$ to decrease sharply (Figure 5(a)). In addition, rotation causes $\sigma_{\mathrm{zz}, \mathrm{R}}$ to become significant (see $\left\langle\sigma_{\mathrm{zz}, \mathrm{R}}\right\rangle / \sigma_{\mathrm{SLJ}}$ in Table II) and stress redistribution due to rotation causes the stress concentrations to broaden. ${ }^{[27]}$ Eventually, the stress distributions at the two ends of the overlap interact and the stresses become more uniformly distributed along the braze. Elasto-plastic 2-D FEA suggests that the von Mises stress becomes more uniform along the braze for 347 SS SLJs brazed with pure silver for $o / t \lesssim 0.5{ }^{[17]}$ while strains measured by digital image correlation ${ }^{[19]}$ suggest that the maximum principal strains are approximately constant for $o / t$ $<1$ for CMSX-4 single-crystal Ni-based superalloy SLJs brazed with BNi-2. These effects are illustrated in Figure 20, which shows a schematic of the distribution of $\tau_{x z}$ along the braze for high, medium, and low overlap ratios.

The $o / t$ dependence of the stress state plays a critical role in SLJ behavior. For example, Chen et al. ${ }^{[25]}$ used elastic 3-D FEA to show that larger $o / t$ brazed SLJs have higher fatigue life than smaller $o / t$ SLJs because of lower "local stress" in the fillet, and that fatigue curves for different overlap ratios collapse into a single curve when plotted as local stress at failure vs cycles to failure.

\section{B. Interpretation of SLJ Strength}

We now combine our knowledge of the stress state with our knowledge of the microstructure to interpret the failure behavior of our $51 \mathrm{H}, 67 \mathrm{~L}$, and $67 \mathrm{H}$ brazed SLJs. We first consider the relation between stress states and failure modes and then demonstrate how those stress states interact with the microstructure to determine joint strength.

\section{Relation of failure modes to stress states}

The changes in stress distribution with overlap length for a given plate thickness have been visualized for brazed or monolithic block SLJs using digital image correlation strain mapping, ${ }^{[19]}$ photoelastic strain imaging, ${ }^{[24,27,28]}$ compliant neoprene models, ${ }^{[24]}$ and finite element analysis. ${ }^{[17,26]}$ Schematics showing the rough size and shape of the plastic zone (region of highest stress) that we expect based on these analyses for samples similar to ours (ductile base metals with strong brazes) for different overlap ratios are presented just before failure in Figures 21(a) through (c), and during failure by peeling and base metal failures in Figures 21(d) and (e), respectively. From Figure 21 it is possible to understand the origin of the three failure modes (fast fracture, peeling, and base metal failure) in our samples as a function of $o / t$ and the structure and properties of the braze and the base metal.

a. Fast fracture At short overlap lengths, stresses are high everywhere along the braze (Figures 20 and 21(a)). A crack may initiate at a stress concentration or flaw anywhere within the braze. Because the volume in which

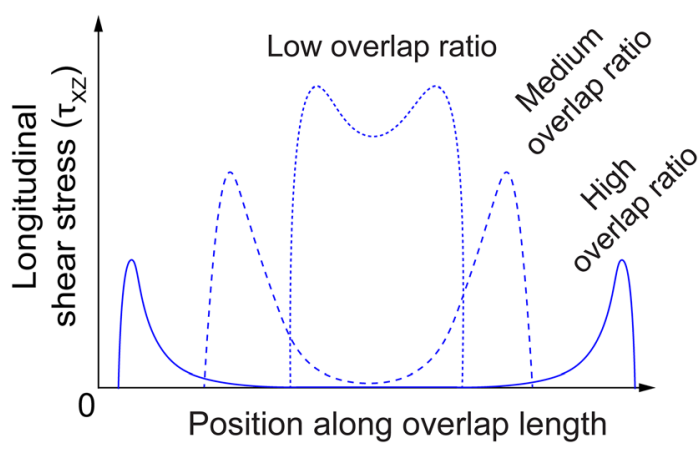

Fig. 20-Schematic braze shear stress distribution for low, medium, and high overlap ratios for the same applied load.

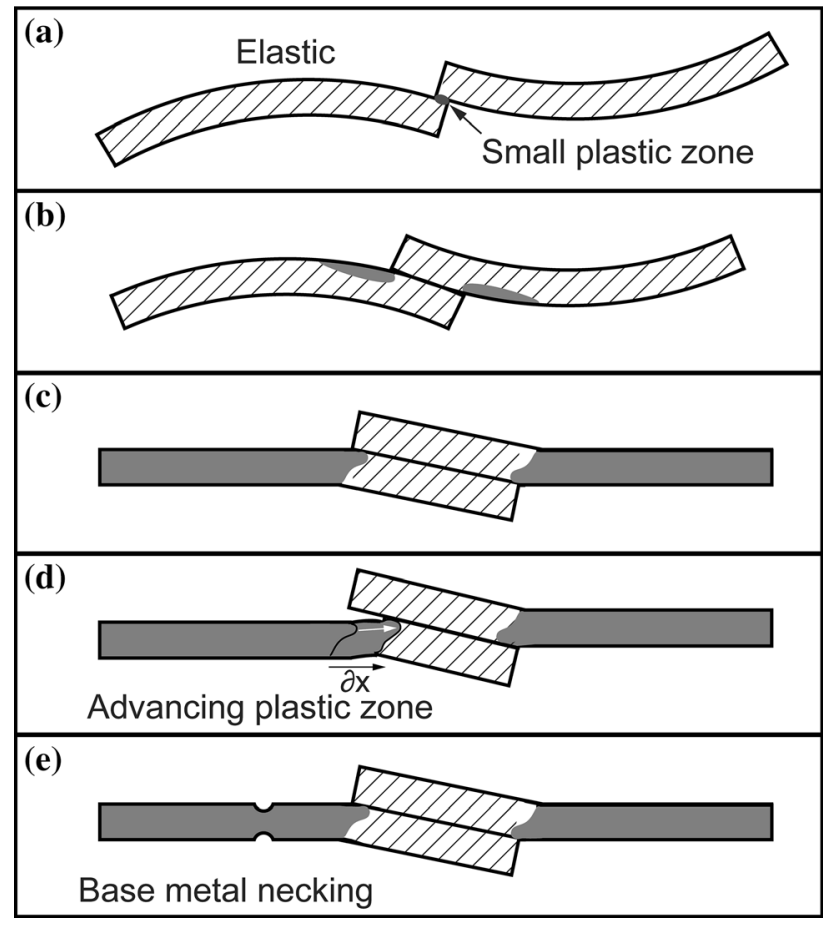

Fig. 21-Schematic distribution of elastic (hatched) and plastic (shaded) strains in SLJs: just before fast fracture in $(a)$ small and $(b)$ medium $o / t$ SLJs and $(c)$ full plate thickness plasticity which progresses to $(d)$ peeling failure or $(e)$ base metal failure. 
plastic deformation may occur is very thin compared to the plate thickness $t$, a triaxial stress state (plane strain) exists at the crack tip which suppresses crack tip plasticity ${ }^{[42]}$ leading to a more brittle fracture process (analogous to the well-known effect of plate thickness on fracture toughness ${ }^{[33]}$ ). Because braze stresses are nonzero everywhere, once a crack forms, the reduction in area increases the stresses on the remaining braze; thus, such fractures are unstable (fast fracture) and the joint strength is determined by the stress needed to initiate crack motion.

As $o / t$ increases (Figure 21(b)), joint stress concentrations decrease, and higher applied loads are needed to cause failure. The stress concentrations at overlap ends begin to separate ("medium overlap ratio" in Figure 20) making cracks more likely to initiate near overlap ends. Nonetheless, as long as a fraction of the SLJ leg remains elastic, the stress at the crack tip only increases with crack motion and unstable fast fracture occurs.

$b$. Peeling As $o / t$ continues to increase, the rotation at a given load continues to decrease, and the load needed to initiate a crack continues to increase. For our samples, beyond a certain overlap length, the applied stress exceeds the base metal yield stress $\left(\sigma_{\text {app }}>\sigma_{\text {yield }}\right)$ before $\sigma_{\mathrm{SLJ}}$ is reached (Figure 5(a)). For $\sigma_{\mathrm{SLJ}}>\sigma_{\text {yield }}$, the gauge sections far from the overlap undergo uniform plasticity and the boundary between elastically- and plastically-deformed material must have a form similar to that shown in Figure 21(c). The fact that braze failures occur at $\sigma_{\mathrm{SLJ}}>\sigma_{\text {yield }}$ has profound effects on the failure mode for displacement-controlled tests. If the maximum braze stresses at overlap ends are high enough to propagate a crack, then for every increment $\delta x$ of crack propagation, a segment of the loaded leg is released from the constraint of the unloaded leg as shown in Figure 21(d). This segment now experiences the full applied stress, and deforms plastically, advancing the elastic/plastic boundary. This plastic deformation relaxes the crack tip stresses and additional crosshead displacement is required to return the crack tip to the fracture stress. Thus, the crack becomes stable and peeling occurs. This process can be seen quite clearly in Figure 10(a), where the upper leg is pulling away from the lower leg and stretching plastically to the same lateral dimensions as the rest of the uniformly strained gauge section. The drop in load that occurs once the peeling crack starts to grow (Figure 6(b)) shows that for peeling, as for fast fracture, $\sigma_{\mathrm{SLJ}}$ is controlled by crack initiation, not by crack propagation. Since the full thickness of the leg is deforming plastically, peeling failures are quite ductile (Figure 6(a)). Finally, when the remaining overlap becomes short enough, low $o / t$ behavior takes over and the final fracture is fast and unstable.

Peeling failures are commonly reported for adhesive SLJs. ${ }^{[38,39]}$ An example of the effect of base metal yield stress on peeling is given by Karachalios et al., who made SLJs from both mild steel $\left(\sigma_{\text {vield }}=270 \mathrm{MPa}\right)$ and high strength steel $\left(\sigma_{\text {yield }}=1800 \mathrm{MPa}\right)$ bonded with a thin epoxy layer (shear strength $=60 \mathrm{MPa}$ ). Although they did not describe the mechanism, they observed that the mild steel yielded before a crack propagated in the epoxy resulting in peeling failure, ${ }^{[38]}$ while fast fracture occurred in the SLJs made from high strength steel at stresses much less than $\sigma_{\text {yield }}{ }^{[37]}$ Peeling is only rarely reported for brazed SLJs (e.g., Reference 16). However, since typically a distinction is made only between base metal and braze failure (e.g., References 3, 14, 19, 20, 25, and 29) or no failure mode details are provided (e.g., References 5 and 18), the true prevalence of peeling vs fast fracture in brazed SLJs is not known.

c. Base metal failure If the braze is sufficiently strong, then it is possible that the sample will fail in the base metal rather than the braze. While this may occur at any $o / t$ depending on the relative strengths of the braze and base metals, the decrease in joint stress concentration at a given load with increasing $o / t$ means that, in many practical systems, braze failures occur at low $o / t$ with a transition to base metal failure at higher $o / t$. Indeed, it is often assumed that a transition to base metal failure with increasing $o / t$ is inevitable (e.g., References 13, 14, 17, and 20). However, this is clearly not the case. If peeling is still occurring when $o / t$ is large enough that the stress state is independent of $o / t$ (e.g., o/t $\gtrsim 6$ in our $67 \mathrm{H} / \mathrm{L}$ data, Figure 5(a)), there is no reason to expect a further transition to base metal failure.

\section{Effect of braze microstructure and base metal} properties

We now add knowledge of braze properties - as coarsely determined here by microstructure (Figures 12, 13, 14, 15, 16, 17, and 18; Table III) - and of base metal properties (principally $\sigma_{\text {vield }}$ ) to provide a complete description of the failure modes in our samples (Figures 5(a), 6, 7, and 8).

Failure in braze joints has long been associated with the presence of hard particles, ${ }^{[1,3-6,8-11,18,21,22,25,26,29,43,44]}$ which can promote fracture not only by increasing the yield stress and lowering ductility, but also by generating large residual stresses (e.g., by differential thermal contraction), concentrating stresses at elastic and plastic discontinuities, and adhesive and cohesive failures at hard particles. Similar behavior is found in metal matrix composites. ${ }^{[45]} \mathrm{In}$ general, the coarser and more anisotropic the hard particles, the more hard particles are present, and the closer together the hard particles are, the lower the strength. ${ }^{[33]}$

This principle is borne out in our study. For all samples that failed in the braze, cracks propagated in regions containing networks of hard particles (Figure 17). In both MBF-67 sample sets, cracks propagated in the multiphase region in the center of the braze (Figures 17(b) and (c)), while in the MBF-51 set, cracks propagated in the base metal adjacent to the braze where $\mathrm{Cr}_{x} \mathrm{~B}_{y}$ particles formed (Figure 17(a)). We thus consider the hard particles that form during brazing to be the source of the "flaws" that lead to braze failures for the samples reported here (with the exception of those with wetting defects, for which the 
unbrazed portion of the overlap may have initiated the fatal flaw). In particular, we consider the flaw size to scale with the size of the IMC particles.

a. Joints made with MBF-67 At the lowest overlap ratios, joints made with $\mathrm{MBF}-67$ fail by fast fracture (Figure 5(a)). As described in Section III-B-i-a., a short overlap leads to high stresses all along the braze (Figures 20 and 21(a)) and unstable crack propagation. As $o / t$ increases, joint stress concentrations decrease so the applied stress needed to initiate the crack increases. Samples continue to fail by fast fracture until $\sigma_{\text {app }} \approx$ $\sigma_{\text {yield }}$, after which the gauge sections become fully plastic and the failure mode switches to peeling (Figures 8 and $21(d))$. We propose two explanations for why $\sigma_{\mathrm{SLJ}}$ is higher for $67 \mathrm{H}$ than for $67 \mathrm{~L}$ at the same $o / t$ for SLJs with $o / t<6$. First, since the base metal yield stress is lower for $67 \mathrm{H}$ (Figure 5(a)), the same amount of rotation produces lower bending stresses due to plasticity; thus, higher applied loads are needed to generate the same stresses in the braze. Second, the braze microstructure in 67L is much coarser (Figures 13 and 14) and contains a larger fraction of hard particles (Figure 16). If cracks initiate in the braze rather than the braze fillet, the coarser microstructure will contain larger flaws and/ or stress concentrations to act as crack-initiation sites. Thus, it is possible that cracks initiate in the braze as long as stresses remain high past the fillet microstructure into the braze, which must be the case since the fillet microstructures persist for only a few hundred $\mu \mathrm{m}$ from the edge (Figure 15). While the stresses may be higher in the braze fillets, the microstructures there are much finer than those in the brazes and are very similar to each other in $67 \mathrm{~L}$ and $67 \mathrm{H}$ (Figure 15). The scatter in the data in Figure 5(a) likely represents the distributions of the crack-initiation sites (flaw sizes) in the different samples.

At $o / t \gtrsim 6, \sigma_{\mathrm{SLJ}}$ becomes approximately constant with $o / t$. Presumably, this is because the rotation becomes small and a weak function of $o / t$ (Table II), extensive plasticity in the gauge sections outside the overlap further reduces the significance of the bending stresses relative to the applied load, and, as described in Section III-A-iii, the stresses at overlap ends become approximately constant with $o / t$ in both magnitude and distribution. The fact that SLJ strength becomes the same in $67 \mathrm{~L}$ and $67 \mathrm{H}$ in this region indicates that there can no longer be a difference in the stress needed for initiating crack motion. A possible explanation is that the stress becomes concentrated in a narrow enough region at the overlap ends that cracks must initiate in the braze fillets, where the microstructures are quite similar (Figures 15(b) and (c)) and not in the regions away from overlap ends, where the microstructures are quite different (Figures 13, 14, 16, 17, and 18). The fact that the scatter in the data is much smaller in this region is consistent with the finer and more uniform microstructure in the fillets (corresponding with smaller and more uniform flaws at which cracks may be initiated).

The origin of the peeling plateaus at the end of the load-displacement curves (Figure 6(b)) is less clear. As the peeling crack progresses, increasing rotation results in a decrease in the applied stress needed to continue to propagate the crack. Eventually the outer fibers in the newly released material (Figure 21(d)) no longer deform plastically which eliminates the plastic hinge. This could slow or stop the rate of rotation with applied displacement possibly causing a plateau. At the same time, the differences in microstructure would lead to different stresses needed to propagate the peeling crack (fracture toughness), which could also play a role in establishing the load at the plateau. While quite reproducible and interesting, this behavior did not affect $\sigma_{\mathrm{SLJ}}$ so it was not analyzed further.

We reiterate that there is no reason to think that an increase in $o / t$ will eventually lead to a transition to base metal failure in SLJs brazed with MBF-67.

b. Joints made with MBF-51 Joints made with MBF-51 are significantly stronger than joints made with MBF-67 at all overlap ratios (Figure 5(a)), consistent with the ductile (Figure 16(d)) IMC-free structure of the braze (Figure 12). Only one of the $51 \mathrm{H}$ samples failed by fast fracture and it had a significant wetting defect $(\sim 25$ pct of the overlap area), so it cannot be compared with the other SLJs at similar $o / t$. It is possible that joints made with MBF-51 having even lower $o / t$ would have failed by fast fracture.

All of the remaining $51 \mathrm{H}$ samples below $o / t=3$ failed by peeling. Since the $51 \mathrm{H}$ and $67 \mathrm{H}$ samples experienced the same braze cycle, the properties of the base metal are expected to be the same. The difference in strength at a given $o / t$ can then be attributed to the strength of the braze, consistent with expectations based on the braze microstructure. Presumably, cracks initiate at the large IMC particles in the fillet (Figure 15(a)) before then propagating in the $\mathrm{SS}$ adjacent to the braze where $\mathrm{Cr}_{x} \mathrm{~B}_{y}$ particles decorate grain boundaries (Figure 17), as observed previously. ${ }^{[3]}$ Note that since there is such a large difference in the microstructure between the fillet (Figure 15(a)) and the braze (Figure 12) in these samples, that it is possible that a crack forms in the fillet at a relatively low stress but that $\sigma_{\mathrm{SLJ}}$ is determined by the stress needed to propagate that crack into the material adjacent to the braze where the $\mathrm{Cr}_{x} \mathrm{~B}_{y}$ particles are located, which is presumably much higher due to the much higher toughness there (smaller and fewer brittle hard particles). Again, the scatter in the data likely reflects the distribution of possible crack-initiation site sizes in the different samples.

For the $51 \mathrm{H}$ samples, as $o / t$ increases and joint stress concentrations decrease, this eventually leads to the case (at about $o / t=4$ ) where the ultimate tensile strength, $\sigma_{\mathrm{UTS}}$, is reached in the base metal gauge section before the peak braze stresses at overlap ends are sufficient to propagate a crack. Thus, at all greater overlap ratios, samples fail by base metal failure at $\sigma_{\mathrm{app}}=\sigma_{\mathrm{SLJ}}=$ $\sigma_{\text {UTS }}$. The exception is the sample at $o / t=4.0$, which failed by peeling, although the sample at $o / t=3.7$ failed in the base metal. These samples are at the transition between peeling and base metal failure. Presumably, the difference was due to the presence of a flaw of critical 
size in the sample with $o / t=4.0$ that allowed a braze crack to form. A second interesting case is the sample at $o / t=5.8$ that was not fully wet out. This sample formed a braze crack that opened during loading and propagated several millimeters before the sample failed in the base metal. Clearly, at $o / t=4.0$ bending strains were still magnifying peak braze stresses enough to allow a crack to propagate along this tough braze once it had formed, while at $o / t=5.8$ these stresses were not enough to cause peeling failure, even when a substantial braze crack was present. These cases emphasize the importance of the interplay between stress state, base metal properties, and braze microstructure in determining failure.

The rotation continues to decline for $o / t>4$ (Table II) such that plastic deformation is less and less concentrated at the overlap ends and more homogeneous throughout the gauge sections as $o / t$ increases. This accounts for the fact that the location of base metal failure moved systematically away from the overlap end as $o / t$ increased.

For comparison, Hartmann and Marsilius showed that the strength of $316 \mathrm{~L} \mathrm{SS}$ butt joints is similar whether brazed with VZ2150 (similar to MBF-51) or with VZ2120 (similar to MBF-20) ${ }^{[11]}$ when the braze is IMC-free. Rabinkin et al. ${ }^{[3]}$ brazed 316L SS SLJs with MBF-51 foils 25 or $50 \mu \mathrm{m}$ thick using multistep braze cycles with maximum conditions ranging from $1175^{\circ} \mathrm{C}$ for 30 minutes to $1190{ }^{\circ} \mathrm{C}$ for 2.5 hours. For joints with $o / t=1.0$ or 1.5 , they found $\sigma_{\mathrm{SLJ}}$ values that ranged from $149 \mathrm{MPa}$ for failures in the braze to $546 \mathrm{MPa}$ for failures in the base metal and were able to correlate their results with IMC formation depending on foil thickness and braze cycle. However, they did not report the effect of the braze cycle on $\sigma_{\text {yield }}$ and reported only one $o / t$ per condition, so it is difficult to interpret their results further.

\section{Testing and Interpretation of Brazed SLJ Strength}

The AWS C3.2 standard was created so that tests performed in different laboratories could be quantitatively compared. ${ }^{[13]}$ However, while we used the standardized AWS C3.2 sample geometry (Figure 2), we had to extend the $o / t$ range beyond the recommendations in the standard and go well beyond typical interpretations to understand the results. When we did, we were able to describe the determinants of the strength in some detail. In this section, we describe changes in testing, reporting, and interpretation of brazed SLJ test results that we believe will facilitate quantitative comparisons across laboratories and clear up several common misconceptions.

$S L J$ test results should be reported as $\sigma_{S L J}$ vs. o/t, and not as $\tau_{\mathrm{SLJ}}$ vs. $o / t$. The AWS C3.2 standard ${ }^{[14]}$ specifies that data are to be presented as both $\sigma_{\mathrm{SLJ}}$ and $\tau_{\mathrm{SLJ}} v s$. both overlap ratio and overlap length. The plot of $\sigma_{\mathrm{SLJ}}$ vs. o/t (Figure 5(a)) correctly describes the observed behavior of the joint: the load-bearing capability first increases then levels off with increasing $o / t$. Furthermore, $\sigma_{\mathrm{SLJ}}$ accurately reflects at least one stress value of interest in the brazement - the engineering stress applied to the sample at failure. In contrast, the plot of $\tau_{\text {SLJ }} v s$. $o / t$ (Figure 5(b)) does not correctly reflect the behavior of the joint; $\tau_{\mathrm{SLJ}}$ declines with increasing $o / t$ although the actual load-bearing capability is increasing. Furthermore, $\tau_{\text {SLJ }}$ does not describe the stress state in the sample at any load or for any $o / t$. The actual stresses are concentrated at the ends of the overlap (Figures 19 and $20)$ and the braze normal stress, $\sigma_{z z}=\sigma_{\mathrm{zz}, \mathrm{L}}+\sigma_{\mathrm{zz}, \mathrm{T}}+$ $\sigma_{\mathrm{zz}, \mathrm{R}}+\sigma_{\mathrm{zz}}, \mathrm{A}$, is typically much larger than the braze shear stress, $\tau_{x z}$, so the SLJ test should never be expected to provide the shear strength of a BFM. Finally, both the transition to steady state behavior and the important differences in strength as $o / t$ increases are obscured when results are presented as $\tau_{\mathrm{SLJ}} v s . o / t$. Paraphrasing ASTM D4896 ${ }^{[39]}$ (for adhesive SLJs), 'The average shear stress at failure is simply the average shear stress that happens to exist in the joint when the stress concentrations reach a critical level and the joint fails. It is not the true shear strength.'

In a strict sense, the average shear stress at failure is meaningful only for a test in which the base metal plates are perfectly rigid so that there is no strain in the SLJ legs and no rotation. ${ }^{[46]}$ All deformation would then be in the bonding layer which would be forced to deform in uniform shear. This might be a good approximation for very compliant and thick adhesives joining very stiff base metal plates, but $\tau_{\mathrm{SLJ}}$ has no fundamental relationship to the failure of brazed SLJs where the braze and base metal properties are of the same order of magnitude.

$A$ wide enough range of o/t should be tested that all failure modes can be observed and reported for each brazement system (BFM, base metal, and braze cycle). Had we followed the AWS standard, our maximum $o / t$ would have been 4 and we would not have seen the transition to the overlap-independent behavior in any of our samples (Figure 5(a)). We thus would have missed the fact that at larger $o / t$ the strength of joints made with MBF-51 was set by $\sigma_{\mathrm{UTS}}$, while the strength of joints made with MBF-67 was determined by braze crack-initiation stresses. Our analysis of the stress state explains this phenomenon and suggests that the common idea that increasing $o / t$ will eventually lead to base metal failure $^{[13,14,17,20]}$ is incorrect. Few have reported peeling behavior, ${ }^{[16]}$ but in a number of cases $\sigma_{\mathrm{SLJ}}$ becomes roughly constant with $o / t$ at a level less than $\sigma_{\mathrm{UTS}},{ }^{[16,29]}$ and it is likely that the maximum $\sigma_{\mathrm{SLJ}}$ in these samples was determined by peeling. Rather than specifying fixed overlap ratios, we recommend testing a wide enough range to capture the full gamut of behavior and to report the failure mode for each sample.

Although the AWS C3.2 standard states that a "two-straight-line function" is to be expected in $\sigma_{\text {SLJ }}$ vs. $o / t^{[14]}$ and although that is what we (Figure 5(a)) and others $^{[13,16,25,29]}$ see, we are not aware of a theoretical justification for this, and there are examples where the transition from low to high $o / t$ behavior occurs gradually. ${ }^{[16,17,19,26,29]}$ More importantly, our results for samples brazed with MBF-67 (Figure 5(a)) and results of others ${ }^{[13,16,25,29]}$ show that the transition from one line to the other does not necessarily correspond with a transition in failure mode, contrary to the expectations 
described in the standard. ${ }^{[13,14]}$ Indeed, it is easy to imagine cases where a two-line curve would be generated with only base metal failure or only fast fracture due to the change in SLJ stress state with $o / t$ depending on the relative properties of the base metal and braze. This emphasizes both that fast fracture and peeling failure modes should be reported and that reports that include too few overlap lengths do not provide sufficient information for useful comparisons.

Load-displacement data and images of deforming samples are useful for interpreting SLJ failures. To the extent that the goal of a study is to understand the strength of a brazed SLJ, as opposed to simply determining it, recording both load-displacement data and video of the failure process allows for a much more detailed analysis of the sequence of events leading to failure.

The yield stress of the base metal should be reported. Since both $\sigma_{\mathrm{SLJ}}$ and the transition from fast fracture to peeling are closely tied to the yield stress of the base metal, accurate measurements of $\sigma_{\text {yield }}$ on samples subjected to the same braze cycle are important to interpreting the failures of brazed SLJs (as suggested in AWS C3.2).

To the extent that these recommendations are followed, we believe that consistent data sets can be generated that will allow the mechanical behavior of different brazed SLJs to be compared in a quantitatively meaningful manner. With the addition of detailed knowledge of the stress state, the microstructure, and the deformation evolution, the data obtained could also be used to interpret joint performance in a consistent manner.

\section{Corrosion Resistance}

Our corrosion results (Figure 11) are consistent with the reports that increasing $\mathrm{Cr}$ and decreasing $\mathrm{B}$ lead to better corrosion resistance by enabling a thicker and more uniform $\mathrm{Cr}$ oxide passivation layer. ${ }^{[3,7,9]}$ James et $a l .{ }^{[7]}$ describe two common effects that degrade the corrosion resistance of Ni-based braze joints: $\mathrm{Cr}$ dilution, which occurs when a BFM has less $\mathrm{Cr}$ than the base metal such that $\mathrm{Cr}$ from the base metal diffuses into the braze, lowering $\mathrm{Cr}$ concentration in the base metal near the braze, and partitioning of $\mathrm{Cr}$ into IMCs with nonmetals $\mathrm{B}, \mathrm{Si}$, and $\mathrm{P}$, lowering $\mathrm{Cr}$ concentration in the material near the IMC particles. Our corrosion results can be understood using these principles as follows:

- In MBF-20, both significant dilution of $\mathrm{Cr}$ into the braze and partitioning of $\mathrm{Cr}$ into $\mathrm{Cr}_{x} \mathrm{~B}_{y}$ precipitates are expected because of low $\mathrm{Cr}$ and high $\mathrm{B}$ concentrations in the BFM relative to the base metal (Table I). These effects reduce the $\mathrm{Cr}$ content in the $\mathrm{SS}$ near the braze, especially near $\mathrm{Cr}_{x} \mathrm{~B}_{y}$ grain boundary precipitates, accounting for the relatively poor corrosion resistance of joints formed with MBF-20.

- In MBF-51, the $\mathrm{Cr}$ concentration is only 1 to $3 \mathrm{wt}$ pct less than that in $316 \mathrm{~L} \mathrm{SS}$ (Table I), so $\mathrm{Cr}$ dilution is expected to be low; and decreased B should result in fewer $\mathrm{Cr}_{x} \mathrm{~B}_{y}$ precipitates, leading to better corrosion resistance compared to joints formed with MBF-20. Nonetheless, there is sufficient B to form $\mathrm{Cr}$-rich grain boundary precipitates in the SS base metal. $^{[3]}$

- The MBF-67 corrosion samples experienced Low-Cycle brazing conditions (Figure 4) and are expected to have the microstructure shown in Figure 13. The much higher $\mathrm{Cr}$ concentration (Table I) prevents $\mathrm{Cr}$ dilution and maintains a higher $\mathrm{Cr}$ concentration in the matrix solid solution despite significant partitioning into $\mathrm{Cr}$-rich IMCs (Figure 13(d); Table III). The low concentration of B means that no $\mathrm{Cr}$-rich grain boundary precipitates form in the SS near the braze (Figure 13). Thus, the corrosion weak points in the other MBF alloys have been eliminated, resulting in better corrosion resistance.

\section{SUMMARY AND CONCLUSIONS}

Our original motivation for this study was to provide a quantitative description of the tradeoffs between strength and corrosion resistance in choosing a "corrosion-resistant" Ni-Cr-Si-B vs. a "very corrosion-resistant" Ni-Cr-P-Mo-Si amorphous foil braze filler metal (BFM) for creating complex layered stainless steel (SS) structures. In addition, we wanted to determine if we could improve the strength of joints brazed with the $\mathrm{Ni}-\mathrm{Cr}-\mathrm{P}-\mathrm{Mo}-\mathrm{Si} \mathrm{BFM}$ by increasing process time and temperature to reduce or eliminate brittle intermetallic compounds (IMCs). We chose single-lap joint (SLJ) tensile tests per American Welding Society (AWS) Standard C3.2 for mechanical characterization because of their simplicity and ubiquity, but quickly discovered that conventional interpretations of this test were inadequate for quantitative comparisons. We thus studied this test in some detail and developed an interpretation that allowed us to understand the behavior of the tested brazement systems (base metal, BFM, and braze cycle) with considerable specificity. The key property of interest is the joint strength defined as the engineering normal stress in the SLJ legs far from the overlap at failure, $\sigma_{\mathrm{SLJ}}$. Our main conclusions are as follows:

Interpretation of the strength, $\sigma_{\mathrm{SLJ}}$, of brazed SLJS tested in tension requires attention to three quantities:

- The sample geometry, particularly the overlap ratio o/ $t$ : Eccentric loading leads to bending moments and overlap rotation making this test highly geometrically nonlinear-that is, the stress state changes significantly with load. Since the rotation needed to align the load axes in the sample legs depends on overlap ratio $(o / t), \sigma_{\mathrm{SLJ}}$ is very sensitive to $o / t$-in our tests it was the most important variable (Figure 5(a)). The stress state can be considered as the sum of a shear-lag stress state plus modifications due to rotation. Shear-lag stresses are highly concentrated near overlap ends with tensile braze 
normal components of higher magnitude than braze shear components. Rotation amplifies shear-lag stresses due to bending and both widens the distribution of those stresses along the braze and adds a braze normal component. While the stress state is mixed, normal components perpendicular to the braze dominate in most instances. For long overlap SLJs, braze stresses are highly concentrated at overlap ends and approach zero away from overlap ends. Depending on the strength of the braze, failure occurs either in the base metal or by peeling (stable fracture) along the braze at constant $\sigma_{\mathrm{SLJ}}$. For low overlap ratios, stresses are concentrated all along the braze and failure occurs by fast (unstable) fracture. Stresses due to transverse shear lag and anticlastic curvature effects may be significant.

- Plasticity in the base metal facilitates overlap rotation, significantly affecting the stress at a given load. Furthermore, we show that peeling failure crack stability is explained by base metal plasticity. If the SLJ gauge section is fully plastic before braze fracture, then each increment of braze crack advance releases a segment of the loaded SLJ leg from the constraint of the unloaded leg to which it was attached. This segment then experiences the full load and deforms plastically. In a displacement-controlled test, this relaxes crack tip stresses and stabilizes the crack.

- Braze microstructure and properties: Hard particles such as IMCs promote fracture by lowering ductility, generating large residual stresses, concentrating stresses at elastic and plastic discontinuities, and providing adhesive and cohesive fracture paths. Microstructure variations between the fillet and the braze must be taken into account. Plasticity in and near the braze reduces stress peaks and distributes stresses more broadly along the braze.

Note that other combinations of base metal and braze properties would give behaviors not reported here. For example, a joint with a weak brittle braze could fail by fast fracture over an extended $o / t$ range yet still display "two-line" $\sigma_{\mathrm{SLJ}}$ behavior. The principles elucidated above can nonetheless be extended to a range of additional brazed SLJ cases.

Quantitative comparison of $316 L$ SS SLJS made with $M B F-51$ and $M B F-67$ :

- When processed to eliminate IMCs, joints made with MBF-51 were strong and corrosion-resistant, with $\sigma_{\mathrm{SLJ}}$ reaching the ultimate tensile strength of the SS base metal $\left(\sigma_{\mathrm{UTS}} \approx 580 \mathrm{MPa}\right)$ by $o / t \approx 4$ and having corrosion resistance about twice that of joints made with MBF-20 (a conventional Ni-Cr-based BFM).

- When processed at typical conditions $\left(1090^{\circ} \mathrm{C}\right.$ for 15 minutes), joints made with MBF-67 had significantly better corrosion resistance-about twice that of MBF-51. However, IMCs limited the strength, resulting in peeling at $\sigma_{\mathrm{SLJ}} \approx 460 \mathrm{MPa}$ for $o / t \gtrsim 6$.

- When processed at the same conditions as joints made with MBF-51 (1195 ${ }^{\circ} \mathrm{C}$ for 60 minutes), joints made with MBF-67 showed significantly reduced volumes of IMCs in the braze. A significant increase in strength $(\approx 80 \mathrm{MPa})$ was also seen, but only at $o / t$ $<6$. Two factors may account for this $o / t$ dependence: First, at high overlap ratios, stresses are confined to the ends of the overlaps where the IMC structure is similar following the different brazing cycles (Figures 15(b) and (c)) while at lower overlap ratios, the stresses may be high enough to initiate fracture further into the braze where the IMC structures are different (Figures 13 and 14). Second, the reduced yield strength of the base metal due to the processing facilitates rotation and reduces the bending stresses at a given $o / t$, increasing the applied load needed for failure. Note that while it may be possible to eliminate IMCs and get stronger brazes with further increases in braze cycle time and/or temperature, the effect on $\sigma_{\mathrm{SLJ}} v s$. $o / t$ will also be modified by further changes in $\sigma_{\text {yield }}$ and strain hardening of the base metal.

Advice about conducting and reporting results of brazed SLJ tensile tests:

- The engineering normal stress in the SLJ legs far from the overlap at failure, $\sigma_{\mathrm{SLJ}}$, correctly represents the strength of the joint and should always be reported. On the other hand, the average shear stress in the braze at failure, $\tau_{\mathrm{SLJ}}$, does not represent a meaningful stress anywhere in a loaded SLJ and has little to no explanatory power.

- Due to the sensitivity of $\sigma_{\mathrm{SLJ}}$ and failure mode to $o / t$, it is necessary to report $\sigma_{\mathrm{SLJ}}$ over the full range of behavior from fast fracture at low $o / t$ to "steady state" behavior where $\sigma_{\mathrm{SLJ}}$ is independent of $o / t$ at high $o / t$ for a complete understanding of a particular brazement system. Had we restricted our measurements to $o / t \lesssim 4$ as recommended in AWS C3.2, many of the insights in the present work would have been lost.

- Peeling, fast fracture, and base metal failure modes should be reported. Peeling (stable braze crack propagation) is an important failure mode that is distinct from fast fracture (unstable braze crack propagation). (Note that deliberate inclusion of peeling in design of joints might offer opportunities to create structures with forgiving "bend before break" failure behavior.)

- While "two-line" $\sigma_{\mathrm{SLJ}}$ vs. o/t behavior may be seen, the transition from a "line" showing an increase in $\sigma_{\mathrm{SLJ}}$ with $o / t$ to a "line" showing $\sigma_{\mathrm{SLJ}}$ constant with $o / t$ is not necessarily due to a change in failure mechanism, but may simply represent a reduction in the effects of joint line rotation with increasing $o / t$. There is no reason to expect a transition to base metal failure at higher $o / t$ in all systems.

- Recordings of load-displacement data synchronized with high-resolution video are useful for understanding the deformation and failure of each joint (e.g., crack propagation, failure mode, etc.) 
- Despite the complex stress state, tensile testing of SLJs remains an effective way to test the mechanical properties of braze joints for the same reasons it was chosen as the original AWS C3.2 standard geometry: it is simple, economical, reproducible, and representative of many actual brazed joints. ${ }^{[13]}$ As we have shown, many useful insights can be obtained from SLJ test data when the true stress state is considered.

- It is worth noting that other common methods for testing the strength of brazed joints also have stress states that are far more complex than is commonly assumed. Double-lap joints tested in tension have shear-lag stresses concentrated at overlap ends (shear and tensile stresses similar to Figure 19), and butt-brazed joints tested in tension have complex triaxial stress states that depend on the thickness-to-diameter ratio of the braze. ${ }^{[42-44]}$ For cases where the actual shear strength of the braze material (i.e., resistance to an applied uniform shear stress) is desired, a test such as torsion of thin-walled-tubular butt joints should be used.

- Use of foil proved propitious for our tests. We did not have to use tack welds to control braze thickness nor machining to control the configuration of the fillets. The molten BFM remained in the overlap and did not flow out. Furthermore, we were able to make large area brazes with overlap lengths of $38.4 \mathrm{~mm}$ (1.5") without the composition variations or coverage inconsistencies that are common with paste. This is evident in the relatively small scatter of our test results.

Our hope is that this work provides a more comprehensive means to understanding and interpreting brazed SLJ data along with a clear comparison of the strength and corrosion resistance of $316 \mathrm{~L}$ stainless steel joints brazed with MBF-51 or MBF-67.

\section{ACKNOWLEDGMENTS}

This work was supported by the National Science Foundation (IGERT-0966045, ENG-1400964), and by the Metglas Hasegawa Fellowship at Cornell University. This work made use of the Cornell Center for Materials Research Shared Facilities which are supported through the NSF MRSEC Program (DMR-1719875). We would also like to thank Joseph D. Carloni and Nicole T. Wiles for their assistance with nanoindentation and Jonathan Gore for assistance with brazing the test samples.
The online version of this article (https://doi.org/10. 1007/s11661-021-06299-1) contains supplementary material, which is available to authorized users.

\section{REFERENCES}

1. American Welding Society: Brazing Handbook, 5th ed., American Welding Society, Miami, FL, 2007.

2. R.K. Shah: Heat Transf. Eng., 2006, vol. 27, pp. 3-22.

3. A. Rabinkin, E. Wenski, and A. Ribaudo: Weld. J., 1998, vol. 77, pp. $66 \mathrm{~S}-75 \mathrm{~S}$.

4. A. Rabinkin: Sci. Technol. Weld. Join., 2004, vol. 9, pp. 181-99.

5. H. Li, X. Zhang, O. Mars, X. Zhao, Q. Lu, and Z. Chen: Weld. World, 2019, vol. 63, pp. 263-75.

6. N.R. Philips, C.G. Levi, and A.G. Evans: Metall. Mater. Trans. A, 2008, vol. 39A, pp. 142-49.

7. J.P. James, F. Bocher, and J.R. Scully: Corrosion, 2009, vol. 65, pp. 511-26.

8. E. Lugscheider and K.D. Partz: Weld. J., 1983, vol. 62, pp. S160-64.

9. T. Hartmann and D. Nuetzel: in LÖT 9th International Conference of Brazing, High Temperature Brazing, and Diffusion Bonding, DVS 263, Aachen Germany, 2010, pp. 42-47.

10. D.Y. Park, S.K. Lee, and Y.J. Oh: Metall. Mater. Trans. A, 2018, vol. 49A, pp. 4684-99.

11. T. Hartmann and M. Marsilius: in LÖT 11th International Conference of Brazing, High Temperature Brazing, and Diffusion Bonding, DVS 325, Aachen Germany, 2016, pp. 239-44.

12. T. Tokunaga, K. Nishio, and M. Hasebe: J. Phase Equilib., 2001, vol. 22, pp. 291-99.

13. American Welding Society: AWS C3.1 Establishment of a Standard Test for Brazed Joints, American Welding Society, New York, 1963, pp. 1-61.

14. American Welding Society: AWS C3.2 Standard Method for Evaluating the Strength of Brazed Joints, American Welding Society, Miami, FL, 2019, pp. 1-17.

15. F.M. Miller and R.L. Peaslee: Weld. J., 1958, vol. 37, pp. $144 \mathrm{~S}-150 \mathrm{~S}$.

16. N. Bredzs and F.M. Miller: Weld. J., 1968, vol. 47, pp. 481S-496S.

17. Y. Flom and L. Wang: Weld. J., 2004, vol. 83, pp. 32S-38S.

18. A. Elrefaey and W. Tillmann: Metall. Mater. Trans. A, 2007, vol. 38A, pp. 2956-62.

19. B. Riggs, A. Benatar, B.T. Alexandrov, and R. Xu: Weld. J., 2017, vol. 96 , pp. $421 \mathrm{~S}-8 \mathrm{~S}$.

20. V.R. Miller and W.L. Falke: RI 8783, Bureau of Mines, 1983.

21. R.K. Shiue, S.K. Wu, and S.Y. Chen: Acta Mater., 2003, vol. 51, pp. 1991-2004

22. M. Pouranvari, A. Ekrami, and A.H. Kokabi: Mater. Sci. Eng. A, 2008, vol. 490, pp. 229-34.

23. M. Goland and E. Reissner: J. Appl. Mech., 1944, vol. 11, pp. A17-27.

24. M.D. Walsh, W. Bryzik, M.C. Young and C.O. Smith: Weld. J., 1971, pp. 39S-41S.

25. J. Chen, V. Demers, E. Cadotte, D. Turner, and P. Bocher: $J$. Mater. Eng. Perform., 2017, vol. 26, pp. 547-53.

26. B. Riggs: Ph.D. Thesis, Ohio State University, 2017.

27. A.S. McLaren and I. MacInnes: Br. J. Appl. Phys., 1958, vol. 9, pp. $72-77$.

28. E. Sancaktar and P.O. Lawry: J. Adhes., 1980, vol. 11, pp. 233-41. 
29. E. Lugscheider, K. Klohn, and R. Lison: Weld. J., 1979, vol. 59, pp. 296S-300S.

30. J.P.M. Goncalves, M.F.S.F. de Moura, and P.M.S.F. de Castro: Int. J. Adhes. Adhes., 2002, vol. 22, pp. 357-65.

31. L.F.M. da Silva, P.J.C. das Neves, R.D. Adams, and J.K. Spelt: Int. J. Adhes. Adhes., 2009, vol. 29, pp. 319-30

32. W.C. Oliver and G.M. Pharr: J. Mater. Res., 1992, vol. 7, pp. $1564-83$.

33. R.W. Hertzberg: Deformation and Fracture Mechanics of Engineering Materials, 2nd ed., Wiley, Hoboken, 1983.

34. V.O. Volkersen: Luftfahrtforschung, 1938, vol. 15, pp. 41-47.

35. R.D. Adams and N.A. Peppiatt: J. Strain Anal., 1973, vol. 8, pp. 134-39.

36. J.A. Harris and R.A. Adams: Int. J. Adhes. Adhes., 1984, vol. 4, pp. $65-78$.

37. E.F. Karachalios, R.D. Adams, and L.F.M. da Silva: Int. J. Adhes. Adhes., 2013, vol. 43, pp. 81-95.

38. E.F. Karachalios, R.D. Adams, and L.F.M. da Silva: Int. J. Adhes. Adhes., 2013, vol. 43, pp. 96-108.
39. ASTM: ASTM D4896, ASTM, West Conshohocken, PA, 2016, pp. $1-6$.

40. S.T. Smith and J.G. Teng: Eng. Struct., 2001, vol. 23, pp. 857-71.

41. I.A. Blech and A.A. Levi: J. Appl. Mech., 1981, vol. 48, pp. $442-45$.

42. N. Bredzs and H. Schwartzbart: Weld. J., 1956, vol. 35, pp. $610 \mathrm{~S}-615 \mathrm{~S}$.

43. H.J. Saxton, A.J. West, and C.R. Barrett: Metall. Trans., 1971, vol. 2, pp. 999-1007.

44. A.J. West, H.J. Saxton, A.S. Tetelman, and C.R. Barrett: Metall. Trans., 1971, vol. 2, pp. 1009-17.

45. M. Finot, Y.L. Shen, A. Needleman, and S. Suresh: Metall. Mater. Trans. A, 1994, vol. 25A, pp. 2403-20.

46. ASTM: ASTM D3983, ASTM, West Conshohocken, PA, 2019, pp. $1-11$.

Publisher's Note Springer Nature remains neutral with regard to jurisdictional claims in published maps and institutional affiliations. 